\title{
LOS INVENTARIOS POST-MORTEM COMO FUENTE PRIVILEGIADA PARA EL ESTUDIO DE LA HISTORIA DE LA CULTURA MATERIAL EN LA EDAD MODERNA*.
}

\author{
por \\ HORTENSIO SOBRADO CORREA \\ Universidad de Santiago de Compostela
}

RESUMEN: En este trabajo se analiza el papel que ha tenido y todavia tiene para los historiadores modernistas, una de las fuentes notariales más ricas en información: los inventarios "post-mortem». Este tipo de escritura, ampliamente criticada por sus omisiones, así como por sus limitaciones en lo que respecta a sus grados de representatividad y fiabilidad, constituye, no obstante, una fuente privilegiada para el estudio de la cultura material de las poblaciones de Antiguo Régimen. Su utilización de forma exhaustiva aproxima al historiador a aspectos del cuadro de vida cotidiano de las gentes que, como la alimentación, la vivienda y el mobiliario doméstico, o la bigiene y el vestido, entre otros, facilitan un mejor conocimiento de las sociedades, tanto rurales como urbanas, del periodo moderno.

PALABRAS ClAVE: Inventarios post-mortem. Fuentes notariales. Cultura material. Edad Moderna.

ABSTRACT: This work analyses the importance for historians, past and present, of one of the richest legal sources in terms of information: the inventories of the deceased. These documents, which have often been criticised not only because of the gaps they contain, but because of their limitations with regard to representativeness or reliability, nevertbeless constitute an ideal source for the study of the material culture of the communities of the Ancien Régime. An analysis of such inventories sheds light on aspects of everyday life such as food, bousing, furniture, bygiene and dress, among

* El presente trabajo ha sido realizado en el marco del Proyecto de investigación: «Evolución de las condiciones materiales de vida, de las pautas de consumo y de las practicas cotidianas del campesinado de la España Atlántica, S. XVI-XIX», con código PB97-0517.

Hispania, LXIII/3, núm. 215 (2003) 825-862 
others, providing a better understanding of both rural and the urban societies of the Modern Age.

KEY WORDS: Inventories of the deceased. Legal sources. Material culture. Modern Age.

«L'histoire de la culture matérielle n'est donc pas une histoire à part, simplement anecdotique: elle est le miroir de toute une societé»

GARNOT, Benoît, La culture matérielle en France aux XVle-XVIIe siècles, París, 1995, p. 134.

La historia de la cultura material, entendida como la aproximación a los distintos modos en que se han satisfecho a través de los tiempos las necesidades humanas elementales de alimento, cobijo y vestido, así como otras más complejas fruto del progreso, constituye un apartado del conocimiento histórico que, como bien ha señalado Benoît Garnot, lejos de reducirse a lo simplemente anecdótico, permite una rica aproximación a las sociedades de Antiguo Régimen. No cabe duda de que, dentro de la variada tipología de los protocolos notariales, los inventarios post-mortem constituyen un tipo de escritura privilegiada para el estudio de la cultura material en el período moderno, dado que permiten al historiador penetrar en la intimidad de los hogares, a través de una «entrada virtual» en el interior de las casas ${ }^{1}$, descubriendo el cuadro de vida diario de las gentes, tanto del mundo rural como del urbano. Para el historiador, este tipo de fuente representa una mina excepcional de datos sobre la vida cotidiana y las estructuras económicas y sociales del pasado, pues permite entrar en contacto directo con las precariedades vitales y la miseria de unos, así como con el confort y la opulencia de otros ${ }^{2}$.

Los inventarios o recuentos de bienes ofrecen una instantánea de las condiciones materiales en las que vivían los hombres y las mujeres de los distintos grupos sociales, suministrándonos impresiones de conjunto sobre los cuadros de vida y las maneras de vivir3; lo que permite reconstruir con cierto detalle las características de la vida doméstica de parte de las poblaciones de Antiguo Régimen, aproximándonos al conjunto de actividades en las que participaban cotidianamente los miembros de la comunidad agrupados en agregados domésticos, y al conjunto de objetos y mobiliario ligados a esas diferentes actividades ${ }^{4}$. La presen-

\footnotetext{
1 BEZARD, Y.: La vie rurale dans le Sud de la Région Parísienne de 1450 a 1560, París, 1929, p. 223.

2 WARO-DesJardins, François: La vie quotidienne dans le Vexin au XVIIIe siècle. Dans l'intimité $d$ 'une societé rurale (d'après les inventaires après décès de Genainville (1736-1810), Pontoise, 1992, p. 5; AGUADO DE LOS REYES, Jesús: «El ajuar familiar en la Sevilla del setecientos», en CHACÓN JiMÉNEZ, Francisco y Ferrer ALós, Llorenc (eds.): Familia, casa y trabajo, Univ. de Murcia, 1997, (pp. 411421), p. 421.

3 GARDEN, Maurice: Lyon et les lyonnais au XVIIle siècle, París, 1970.

${ }_{4}^{4}$ TARDIEU, Suzanne: La vie domestique dans le Mâconnais rural préindustriel, París, 1964, p. 23.
} 
cia de este tipo de escritura notarial en los archivos de países de prácticamente toda Europa occidental, así como de centroeuropa, como ocurre en los ricos archivos alemanes, búlgaros, húngaros, o incluso turcos y canadienses, entre otros, da un carácter de universalidad a la fuente, que añade su interés, por cuanto, mediante una explotación sistemática permite fructuosas comparaciones en el tiempo y el espacios.

A través de estas líneas no pretendemos realizar un análisis exhaustivo del papel de los inventarios en el campo de la Historia de la cultura material del período moderno, sino hacer una simple reflexión acerca de la importancia que esta fuente notarial ha tenido y todavía tiene en esta interesante parcela de la Historia, pues, no cabe duda de que los estudios realizados en el seno de la historiografía francesa, y como traslación de éstos, en otros ámbitos de investigación europeos, han mostrado como los inventarios constituyen una fuente irremplazable para conocer más de cerca la cultura material de las poblaciones de la Edad Moderna ${ }^{6}$, aunque su utilización plantee una serie de problemas que es necesario tener presentes.

En las décadas de los 70 y 80 del siglo pasado tiene lugar un notable esfuerzo por parte de la historiografía francesa por consolidar a los protocolos notariales (y dentro de éstos a los inventarios post-mortem), como fuente privilegiada para el conocimiento de las sociedades de Antiguo Régimen, algo apreciable, por ejemplo, a través de las distintas aportaciones al Coloquio de Estrasburgo celebrado en el año 1978, o en las presentadas en el Coloquio de Clermont-Ferrand de 1982, entre otros ${ }^{7}$, y en las que se observa un creciente interés por la explotación de los inventarios post-mortem para el análisis de la economía, así como de la historia socio-cultural del período moderno ${ }^{8}$. Asimismo, autores de la talla de Pierre Goubert, Pierre Deyon, Richard Gascon o Maurice Garden, entre otros, ya habían mostrado las inmensas posibilidades de los inventarios urbanos para el estudio de la realidad cotidiana vivida en las ciudades de Antiguo Régimen ${ }^{9}$, al tiempo que una multitud de trabajos de historia rural han

5 BAULANT, Micheline: «L'analyse par ordinateur des inventaires après décès de la région de Meaux", en Les Actes Notariés. Source de l'bistoire sociale, XVIe-XIXe siècles. Actes du Colloque de Strasbourg (1978), Istra. Estrasburgo, 1979, pp. 197-203.

6 GARNOT, Benoît: La culture matérielle..., p. 145.

7 Les Actes Notariés. Source de l'bistoire sociale, XVIe-XIXe siècles. Actes du Colloque de Strasbourg (1978), Istra. Estrasburgo, 1979; Elevage et vie pastorale dans les montagnes d'Europe au Moyen Age et à l'Epoque Moderne, Clermont-Ferrand, 1982.

8 Cf. entre otros los trabajos de JACQUART, Jean: «L'utilisation des inventaires après décès villageois. Grille de dépouillement et apports», en Les actes notariés..., pp. 187-196; RoCHE, Daniel, ARNETTE, Rémy y ARDELlier, F.: «Inventaires après décès Parísiens et culture matérielle au XVIIIe siècle», en Les actes notariés..., pp. 231-240; QUENIART, Jean: «L'utilisation des inventaires en Histoire socio-culturelle», en Les actes notaries..., pp. 241-255.

9 Goubert, Pierre: Beauvais et le Beauvaisis. De 1600 à 1730, París, 1960; DeYON, Pierre: Amiens capitale provinciale. Étude sus la société urbaine au 17e siècle, París, 1967; GASCON, Richard: 
revelado la utilidad de los recuentos de bienes rurales para el análisis de aspectos como la economía campesina, o el cuadro de vida de la población.

En el caso de la historiografía española, cabe destacar la temprana labor desarrollada por el profesor Eiras Roel, quien a partir de 1965, apoyado en un selecto equipo de modernistas gallegos, se esforzó en introducir en el país las propuestas de $A$ nnales ${ }^{10}$, aplicándolas a través de una serie de investigaciones, centradas en tratar de indagar en el comportamiento demográfico y socioeconómico de algunas zonas de la Galicia rural, por medio de la realización de monografías de Historia rural de carácter comarcal, en las que fue adquiriendo un destacado protagonismo el empleo de fuentes notariales ${ }^{11}$.

Tanto las I Jornadas de Metodología Aplicada de las Ciencias Históricas, celebradas en Santiago de Compostela en Abril de 1973, como más tarde, el II Coloquio de Metodología Histórica Aplicada - La Documentación Notarial y la Historia-, (Santiago, 1982), constituyeron un destacado lugar de encuentro entre los historiadores españoles, así como una estupenda oportunidad de contacto con las líneas de investigación europeas ${ }^{12}$. Ambas Jornadas, organizadas por el Departamento de Historia Moderna de la Universidad de Santiago, y con la presencia de destacadas figuras de la historiografía francesa - E. Labrousse; $R$. Mousnier. P. Goubert, F. Lebrun, etc.--, contribuyeron, sin duda, a impulsar la renovación de la historiografía modernista española. En esta labor de introducción de las innovaciones de la investigación histórica europea y renovación de la Historia Moderna española no faltaron algunas reflexiones metodológicas que trataron de profundizar en la incorporación de la documentación notarial como fuente rica en información, poniendo de relieve los pros y los contras de

Gran commerce et vie urbaine au XVIe siècle. Lyon et ses marchands (environs de 1520-environs de 1580), París, 1971; GARDEN, Maurice: opus cit.

10 Cf. Domínguez Castro, L. y Quintana, X. R.: «Renovación en la historiografía española: Antonio Eiras Roel y la recepción del movimiento de Annales en Galicia», en BARROS, Carlos (ed.): Historia a Debate, I, A Coruña, (1995), pp. 319-342. Para una visión de la evolución de la investigación modernista gallega Cf. SAAVEDRA FERNÁNDEZ, Pegerto: «La investigación sobre el Antiguo Régimen gallego: estado de la cuestión, problemas y sugerencias», en CASTRO PÉREZ, Xavier y de JUANA, Jesús (eds.), IV Xornadas de Historia de Galicia, Ourense, 1988, pp. 147-174.

$"$ Cf. BARreIRo MALLón, Baudilio: La Jurisdicción de Xallas en el siglo XVIII: Población, sociedad y economía, Univ. de Santiago, 1973; RodrígueZ FERreIRo, Hilario: La tierra de Trasdeza. Una economía rural antigua, Santiago, 1973; PÉREZ GARCÍA, José Manuel: Un modelo de sociedad rural de Antiguo Régimen en la Galicia costera, Santiago, 1979; Bravo CORES, Daniel: El Barbanza Meridional en el Antiguo Régimen. Población, sociedad y economía, Santiago, 1979, (Memoria de Licenciatura inédita); SAAVEDRA FERNÁNDEZ, Pegerto: Economía rural antigua en la montaña lucense. El Concejo de Burón, Santiago de Compostela, 1979 y Economía, política y sociedad en Galicia. La provincia de Mondoñedo, 1480-1830, Madrid, 1985; ReY CASTElaO, Ofelia: Aproximación a la Historia rural en la comarca de la Ulla (siglos XVII y XVIII), Santiago, 1981.

12 Cf. Actas I Jornadas de Metodología Histórica Aplicada, III. Historia Moderna, Univ. de Santiago, 1975, y Actas II Coloquio de Metodología Histórica Aplicada. La Documentación Notarial y la Historia, Univ. de Santiago, 1984, 2 vols.

Hispania, LXIII/3, núm. 215 (2003) 825-862 
su utilización para el análisis de la Historia económica y social de las poblaciones europeas de Antiguo Régimen.

Pocos años después de la celebración de las I Jornadas, la publicación de los volúmenes colectivos, Las Fuentes y los Métodos (Santiago, 1977) y La Historia Social de Galicia en sus fuentes de Protocolos (Santiago, 1981), es prueba evidente del protagonismo que van adquiriendo las fuentes notariales en el estudio de una diversificación temática cada vez mayor de la Historia en el período moderno. Asimismo, las contribuciones a los Estudis Històrics $i$ Documents dels Arxius de Protocols (Barcelona, 1980), hacen hincapié en el papel que la documentación de Protocolos Notariales va tomando en ese momento en el seno de la Historiografía Modernista ${ }^{13}$.

La celebración de estos Coloquios, así como la publicación de los volúmenes colectivos señalados, contribuyó, sin duda, a la progresiva consagración de los protocolos notariales como fuente autónoma, lo que fomentó el empleo de escrituras como los inventarios post-mortem en el análisis de aspectos como la economía campesina o la historia social y de las mentalidades ${ }^{14}$, y que luego fueron progresivamente utilizados por la historiografía modernista española para el estudio de los niveles materiales y mentales de la población del período moderno ${ }^{15}$. No obstante, es preciso señalar que en España, el estudio de la cultura material y el consumo, en relación con los niveles de vida de las poblaciones del Antiguo Régimen, constituye uno de los temas más desatendidos de la histo-

13 Martínez SARrión, Ángel (dir.): Estudis Històrics i Documents dels Arxius de Protocols, VIII, Barcelona, 1980.

14 Cf. Eiras Roel, Antonio y Villares PaZ, Ramón: «Información serial de inventarios postmortem. Área compostelana, 1675-1700», en Actas I Jornadas de Metodología..., pp. 183-202; EIRAS ROEL, Antonio: «Tipología documental de los protocolos gallegos», en EIRAS ROEL, Antonio y cols.: La Historia social de Galicia en sus fuentes de protocolos. Universidad de Santiago, 1981; PÉrez GARCíA, José Manuel: «Los inventarios post-mortem como indicadores de la riqueza ganadera. Galicia occidental (1600-1669)», en Actas II Coloquio..., pp. 297-316; SAAVEDRA FERnÁNDEZ, Pegerto: «Evolución de una agricultura de autoconsumo a través de los inventarios post-mortem: La Galicia cantábrica, 1600-1800», en Actas II Coloquio..., I, pp. 317-334; BENNASSAR, Bartolomé: «Los inventarios post-mortem y la historia de las mentalidades", en Actas II Coloquio..., II, pp. 139-146; BARREIRO MALLÓN, Baudilio: «Las clases urbanas de Santiago en el s. XVIII: definición de un estilo de vida y de pensamiento", en EIRAS Roel, Antonio et alii: La Historia social..., pp. 449-474.

15 Castañeda Peiron, L.: «Ensayo metodológico sobre los inventarios post-mortem en el análisis de los niveles de vida material: el ejemplo de Barcelona entre 1790-1794», en Primer Congrés d'Història Moderna de Catalunya, Barcelona, 1984, V. I, pp. 757-769; ROZADOs FERNÁNDEZ, M.A.: «El marco material de la vida familiar en la Galicia de Antiguo Régimen», en BERMEJO BARRERA, J.C. (ed.): Parentesco, familia y matrimonio en al Historia de Galicia. Santiago, 1989, pp. 79-94; GARCía GARCía, M. Magdalena: «Condiciones de vida material de los vigueses según los inventarios post-mortem en los siglos XVII y XVIII», en Boletín del Instituto de Estudios vigueses, n 2, 1996, pp. 107-118; PÉreZ GarCíA, José Manuel: «Niveaux de vie et traditions culturelles dans les campagnes du León entre 1700-et 1850», en Histoire E Sociétés Rurales, (1997), n 8, (pp. 61-92), p. 61; Cf. también las diversas aportaciones a TORRAS, Jaume y YUN CASALILLA, Bartolomé (dirs.): Consumo, condiciones de vida y comercialización. Cataluña y Castilla, siglos XVII-XIX, Ávila, 1999. 
riografía, con relación a otros países europeos como Inglaterra y Francia ${ }^{16}$, en especial, en lo que se refiere al mundo rural, por lo que en este trabajo, si bien haremos referencias a la historia urbana, como se verá, prestaremos una mayor atención al ámbito rural.

En Francia los historiadores que se han ocupado del estudio de la cultura material se interesaron por el mundo de los objetos esencialmente desde la perspectiva de una historia de la vida privada, de la configuración de un ambiente doméstico de intimidad ${ }^{17}$, lo que, en cierto modo, contrasta con la Historia cultural anglosajona, principalmente americana, que parece centrar su interés en la cultura de masas ${ }^{18}$. Las obras de Daniel Roche (Le peuple de Paris (1981)), y de Annick Pardailhé-Galabrun (La naissance de l'intime (1988)), y otras que siguieron su estela en el ámbito de la historiografía francesa, o en la de otros países como España, contribuyeron a una arqueología de lo cotidiano, a una reconstrucción del interior de los hogares, gracias al estudio serial de una fuente notarial privilegiada, aunque con algunas limitaciones. En los años noventa del siglo pasado, ese interés por la cuantificación de los objetos presentes en los agregados domésticos y que conforman la cultura material va dejando paso a una mayor preocupación por la reconstrucción del contexto en el que se ubican dichos objetos ${ }^{19}$, buscando una lectura social de la cultura material, a través de la interpretación de la difusión de los objetos, como modelos de consumo, en los que se observa una auténtica revolución de los objetos, así como de las apariencias ${ }^{20}$.

16 Cf. Pérez García, José Manuel: «Niveaux de vie..., p. 61; TORRAS, Jaume y Yun CaSALILLA, Bartolomé (dirs.): Consumo, condiciones de vida..., p. 27. Para una visión rápida de la bibliografía sobre los niveles de vida, y acerca de la relación entre cultura material y consumo Cf. DE VRIES, Jan: «Betweeen purchasing power and the world of goods: understanding the household economy in early modern Europe», en BREWER, Jhon y PORTER, Roy (eds.): Consumption and the world of goods, Londres, 1993, pp. 85-132; SChuURMAN, A. y WALSH, L. (eds.): Material culture: Consumption, Life-style, standard of Living, 1500-1900, en Eleventh International Economic History Congress, Milán, 1994.

17 ARIÈs, Philippe y DUBY, George (éd.): Histoire de la vie priveé, París, 1985-1988, 5 vols.

18 Cf. BREWER, Jhon y PORTER, Roy: Consumption and the world..., op. cit.

19 Poulot, Dominique: «Une nouvelle Histoire de la culture matérielle?», en Revue d'bistoire moderne et contemporaine, 44-2 (Avril-Juin, 1997), pp. 345-357.

${ }^{20}$ Para el caso francés Cf. CORNETTE, Jöel: «La Révolution des objets. Le París des inventaires après déces (XVIIe-XVIIIe sièclees)", en Revue d'Histoire Moderne et Contemporaine, XXXVI, (1989), pP. 476-486; Roche, Daniel: La culture des apparences. Une bistoire du vêtement XVIle-XVIIle siècle, París, 1989; del mismo autor: La France des Lumiéres, París, 1993, pp. 503 y ss.; y Histoire des choses banales. Naissance de la consommation dans les sociétés traditionelles (XVIIe-XIXe siècles), París, 1997; GARNOT, Benoît: Le peuple au siècle des Lumières. Échere d'un dressage culturel, París, 1990, pp. 154 y ss. y Un déclin: Chartres au XVIIIe siècle, París, 1991, pp. 195 y ss.; Sobre la existencia de una revolución del consumo en la sociedad inglesa antes de la Revolución Industrial Cf. MCKENDRICK, Neil: «The consumer Revolution of Eighteenth-Century England», en MCKENDRICK, Neil, BREWER, J. y Plumb, J.H. (eds.), The Birth of a consumer society. The Comercialization of Eighteenth-Century England. Londres, 1982, pp. 9-33.

Hispania, LXIII/3, núm. 215 (2003) 825-862 


\section{LA FUENTE: PROBLEMAS INHERENTES A LA UTILIZACIÓN DE LOS INVENTARIOS POST-MORTEM}

Los problemas derivados del empleo de recuentos de bienes ya habían sido puestos de manifiesto en su momento por historiadores de la talla de Pierre Goubert, y más tarde recalcados por otros como Daniel Roche, en el ámbito francés ${ }^{21}$, pero también han sido apuntados por historiadores de nuestro país ${ }^{22}$, quienes han ido destacando las peculiaridades que presenta dicha fuente en cada región.

Una de las primeras dificultades que plantea la utilización de los inventarios deriva de la escasez de este tipo de escrituras en algunas zonas. Así, por ejemplo, en Galicia, se encuentran disponibilidades bien distintas, ya que mientras que en algunas jurisdicciones del interior lucense, o en determinados cotos del área mindoniense la realización de inventarios constituía una práctica más o menos frecuente entre la población rural, sin embargo, en otras zonas del territorio gallego, situadas tanto en el litoral occidental, como en áreas de transición, o incluso de la Galicia interior - Celanova (Ourense), por ejemplo-, estas escrituras son mucho menos numerosas ${ }^{23}$. La causa de esta gran heterogeneidad geográfica en cuanto a la mayor o menor presencia de escrituras de recuento de bienes en los protocolos gallegos, no está demasiado clara; en alguna ocasión se ha apuntado la interrelación entre la mayor o menor abundancia de inventarios y el tamaño de las circunscripciones judiciales, pues en determinadas zonas en las que predominaban las grandes jurisdicciones estas escrituras notariales eran menos numerosas, mientras que en los pequeños cotos eran más abundantes ${ }^{24}$, sin embargo, esto no siempre se cumple, y también habría que tener presentes posibles razones de tipo cultural, vinculadas con la diversidad de costumbres de cada zona, o incluso cierta especialización de los escribanos en determinados tipos de escrituras.

21 Goubert, Pierre: Beauvais..., p. 151; Roche, Daniel: Le Peuple de París, París, 1981.

22 EIras Roel, Antonio y Villares PaZ, Ramón: «Información serial de inventarios postmortem..., op. cit.; YUN CASALILLA, Bartolomé: «Inventarios post-mortem, consumo y niveles de vida del campesinado del Antiguo Régimen. Problemas metodológicos a la luz de la investigación internacional», en TORRAS, Jaume y YUN CASALILLA, Bartolomé (dirs.): Consumo, condiciones de vida..., (pp. 27-40); SOBRADO CORREA, Hortensio: Las tierras de Lugo en la Edad Moderna. Economía campesina, familia y berencia, 1550-1860, A Coruña, 2001, pp. 58 y ss.

${ }^{23}$ Mientras que en tierras de Lugo y de Mondoñedo los inventarios son relativamente abundantes, sin embargo en áreas del litoral, e incluso del interior, como ocurre en tierras de Celanova (Ourense), los inventarios son escasos. SOBRADO CORREA, Hortensio, Las tierras de Lugo..., p. 58; SAAVEDRA FERNÁNDEZ, Pegerto: «Evolución de una agricultura de autoconsumo..., pp. 318-319; RODRíGUEZ FERNÁNDEZ, Delfina, «Desigualdades sociales y criterios de consumo diferenciados. Cultura material y nivel de vida en la Galicia interior, Celanova (1630-1850)», Cuadernos Feijonianos de Historia Moderna, I, Santiago, (1999), (pp. 193-231), p. 201.

${ }^{24}$ SAAvedra FernándeZ, Pegerto: «Evolución de una agricultura..., pp. 318 y ss. 
Asimismo, hay que tener presente que el inventario post-mortem es un tipo de escritura notarial que presenta notables variaciones en su tipología y grado de información, ya que su elaboración no es plenamente objetiva, sino que depende de la propia personalidad y criterio personal del escribano que lo redacta y de la de sus clientes, lo que explica la gran heterogeneidad de tipos de recuentos que nos podemos encontrar, así como el hecho de que cuando la fortuna a inventariar es grande la descripción tiende a ser minuciosa ${ }^{25}$.

Además de la mayor o menor eficiencia y afán pormenorizador del escribano que los realiza, así como del tipo de clientela al que van dirigidos, los inventarios pueden presentar peculiaridades propias en el tipo de información que incluyen y en su grado de minuciosidad, dependiendo del área geográfica en la que se llevan a cabo; puesto que son perceptibles claros matices en la forma de elaboración de dicha escritura notarial en función de las costumbres del país o incluso de la región en la que se realiza un recuento de bienes. Dependiendo de los países, los inventarios post-mortem tienen características propias y presentan diferentes grados de detalle en sus informaciones. Por ejemplo, en la tipología establecida por Micheline Baulant en los años ochenta ${ }^{26}$, señalaba una clara heterogeneidad a la hora de confeccionar los inventarios, distinguiendo la existencia de cuatro modelos básicos: un primer tipo que empleaba un orden lógico en sus descripciones siguiendo distintos esquemas posibles, agrupando, por ejemplo, los utensilios de cocina, vajilla, etc., tendencia que caracterizaría al modelo alemán ${ }^{27}$, y que también se daría hacia el norte europeo, hasta Finlandia. En segundo lugar estaría el modelo inglés, también con gran importancia en Francia, en el que predominaría un tipo de inventario que describe los objetos estancia por estancia; y en tercer lugar uno mixto, que consistiría en la descripción cuarto por cuarto, pero dentro de cada uno se sigue un orden lógico, ordenando los objetos por su afinidad en categorías. En último lugar estarían los inventarios hechos sin ningún tipo de orden, por lo que se trataría del arquetipo más pobre, que se puede encontrar en varias áreas de Europa, incluida España, combinado con los modelos anteriores; así, por ejemplo, en muchas zonas de la Galicia rural este tipo de inventario «sin orden» era más o menos común ${ }^{28}$.

25 Pellegrin, Nicole y PÉret, Jacques: «Meubles et vêtements dans les inventaires après décès poitevins au XVIIIle siècle. Une source et ses problèmes», en GOY, Joseph y WALLOT, Jean Pierre (dir.), Évolution et éclatement du monde rural. Structures, fonctionnement et évolution différentielle des societés rurales françaises et québécoises XVIle-XXe siècles, París, 1986, pp. 469-473.

${ }^{26}$ BAULANT, Micheline: «Typologie des inventaires après décès», en VAN DER WOUDE, A. D. y Schuurman, Anton (eds.): Probate inventoires. A new source for the historical study of wealth, material culture and agricultural development, Utrecht, 1980, (pp. 33-42), p. 39.

27 Sobre la información que ofrecen los inventarios alemanes Cf. BORSCHEID, Peter: «Les inventaires Wurtembergeois: une chance pour l'Histoire sociale programme et premiers résultats», en Les actes notariés..., pp. 205-229.

${ }_{28}$ Por ejemplo, en el casi millar de inventarios analizados en nuestras investigaciones sobre el interior de la antigua provincia de Lugo, predominan de forma clara inventarios sin ningún tipo de orden. Cf. SOBRADO CORREA, Hortensio: Las tierras de Lugo..., p. 61. 
En el distinto grado de información y detalle que ofrecen los inventarios, a parte de la personalidad del escribano y de sus clientes, o de las particularidades propias de cada zona, asimismo, hay que tener presente que la diversidad de las causas que motivan la realización de un recuento de bienes, también puede tener importantes repercusiones sobre el total de bienes inventariados, y su correspondiente valor. La aplicación jurídica que tenga un recuento influye de forma destacada en el volumen y valor de lo inventariado, de forma que se observarán diferencias sustanciales entre un recuento que se haga a causa de la muerte del cabeza de familia, o de su cónyuge, por la celebración de un matrimonio o de segundas nupcias, motivado por la existencia o previsibles litigios de herencia, por deudas, por disolución de comunidad, o por otras cuestiones que hagan necesaria la realización de dicha escritura notarial. Por ejemplo, en la zona francesa de Poitou, Nicole Pellegrin y Jacques Péret observan como el doble funcionamiento jurídico del inventario, que corresponde a dos situaciones financieras distintas: por un lado, una circunstancia de endeudamiento, y por otro una situación de activo consistente, da lugar a una clara diferenciación entre los recuentos de bienes pedidos por un señor, un acreedor o bien por herederos inquietos, con un nivel de bienes inventariados y un valor muy inferior a la media local, mientras que, por otra parte, los inventarios hechos por disolución de comunidad son siempre superiores en volumen y valor a la media total de todos los inventarios ${ }^{29}$. Ante situaciones problemáticas, cuando los herederos no son conocidos, la iniciativa del acta recae en los señores, o cuando existen deudas, son los acreedores los que solicitan el recuento de bienes; en estos casos, las actas de recuento ofrecen niveles muy bajos de bienes, algo que caracteriza a la región francesa de la Gâtine, (en donde casi la mitad de los inventarios eran de origen judicial y señorial), lo que contrasta con el caso de inventarios elaborados por disolución de comunidad, que muestran valores bastante superiores a la media.

Aunque la finalidad de un número importante de inventarios post-mortem responde al deseo de asegurar la transmisión a los herederos de unos bienes, a fin de que no se menoscaben antes de que los herederos alcancen la mayoría de edad, y por lo tanto son solicitados por familiares del difunto, no obstante, en varias zonas de Europa existe un importante porcentaje de inventarios realizados a instancias de las justicias, a fin de salvaguardar los intereses de los hijos menores, como ocurre en determinadas regiones de Francia como la de Poitou, en Holanda, o en el caso de nuestro país, en diversas áreas de Castilla y de Galicia como la villa de Cuenca de Campos, o el área rural de los alrededores de Santiago de Compostela, entre muchas otras ${ }^{30}$.

29 Pellegrin, Nicole: «L'habillement rural en Poitou au XVIIIe siècle d'apès les inventaires après décès", en GOY, Joseph y WALLOT, Jean Pierre (dir.): Évolution et éclatement du monde rural..., (pp. 475-497), p. 477; Pellegrin, Nicole y PÉRET, Jacques: «Meubles et vêtements..., p. 470.

30 WIJSENBECK, Thera: "Delf in the eighteenth century», en VAN DER WOUDE, A. D. y Schuurman, Anton (eds.), Probate inventoires..., (pp. 157-176), pp. 160-161; Yun CaSalilla, Barto- 
Un inventario ideal tendría que tener varias cualidades básicas: ser exhaustivo, preciso, exacto, detallado y con evaluación del valor de los objetos que describe ${ }^{31}$, sin embargo, en la práctica esas cualidades son inexistentes en la mayoría de los inventarios post-mortem del período moderno. El inventario es una fuente ampliamente elogiada por la riqueza de sus datos, pero asimismo muy criticada por sus deficiencias y omisiones. Son muchas las críticas que los historiadores han vertido acerca de los problemas que plantea el uso de este tipo de fuente notarial; entre los aspectos más reprochados a los recuentos de bienes destacan los que hacen referencia a sus grados de representatividad y frabilidad, falta de homogeneidad, así como a las omisiones más o menos sistemáticas de información que presentan.

Por lo que respecta al grado de representatividad, hay que señalar que, si bien, en teoría los inventarios constituyen un tipo de documentación que incluye a todos los estratos de la sociedad, en la práctica dejaban de lado a los sectores más desfavorecidos de la misma, por lo que su nivel de representatividad social es limitado ${ }^{32}$. En el mundo rural, los inventarios se refieren, por lo general, a las capas medias y superiores del campesinado ${ }^{33}$, pues los sectores más humildes, como los campesinos con escasas tierras o los jornaleros, apenas podían sufragar los gastos derivados de una escritura notarial como ésta, lo que puede extrapolarse al ámbito urbano, en el que el coste de este tipo de acta era muy elevado para los sectores populares, pues equivalía al sueldo de varias jornadas de trabajo ${ }^{34}$, por lo que, en cierto modo, se podría hablar de la existencia de una relación entre el costo del acta y la selección social.

En el Antiguo Régimen los recuentos de bienes sólo recogen un porcentaje de los difuntos totales, que varía ostensiblemente dependiendo de las distintas zonas, así como si se trata de un área rural o urbana ${ }^{35}$, lo que limita en gran

lomé: «Inventarios post- mortem, consumo..., p. 32; VILLARES PAZ, Ramón: Los inventarios post mortem como fuente para el estudio de la Historia rural y la economía agraria. Comarca de Santiago, 1675-1715, Santiago, 1973 (Memoria de Licenciatura inédita), p. 10; también para la misma zona de Santiago Cf. ROZADOS FERNÁNDEZ, Màría Ángeles: Campo y ciudad: niveles materiales y mentalidades en el Siglo XVII a través de los inventarios post-mortem, Santiago, 1986 (Memoria de Licenciatura inédita), pp. 28-29.

31 BAULANT, Micheline: «Typologie des inventaires..., p. 39.

32 Cf. WIJSENBECK, Thera: «Delf in the eighteenth..., p. 165-170; OvERTON, Mark: «English probate inventoires and the measurement of agricultural change», en VAN DER WOUDE, A. D. y SChuUrman, Anton (eds.), Probate..., pp. 205-215.

33 GOUBERT, Pierre: Beauvais..., p. 152.

34 Por ejemplo, en París el coste de un inventario era de alrededor de 15 a 20 libras, y en 1780 de 30 a 40 libras, lo que equivalía al sueldo de 20 jornadas de trabajo. PARDAILHÉ-GALABRUN, Annick: La naissance de l'intime. 3000 foyers Parísiens, XVIIe-XVIIIe siècles, París, 1988, p. 30.

35. Por ejemplo en el caso canadiense, en la ciudad de Quebec, a principios del XIX los inventarios afectan a poco más del $10 \%$ de los difuntos, mientras que en el campo esa representatividad supera el $55 \%$. Cf. MORIN, Yvan, «La representativité des inventaires après décès... Québec au début du XIXe siècle», en RHAF, 34 (1980-1981), pp. 515-553; PAQUET, G. y WALlot, Jean Pierre: «Une spectrographie des genres de vie dans la societe rurale Bas-Canadienne (1792-1835)»,

Hispania, LXIII/3, núm. 215 (2003) 825-862 
medida su grado de representatividad. Además, el mundo de los errantes, inestables y emigrantes escapa a los inventarios, pues este tipo de escrituras limita su radio de acción a una sociedad básicamente estable ${ }^{36}$.

Varios autores han reprochado a los inventarios su escasa representatividad para el conjunto de la población, apoyándose en el hecho de que este tipo de recuentos de bienes solía hacerse al final de la vida, registrando primordialmente las fortunas de personas de edad avanzada, lo que acentuaría los contrastes y podría dar una idea falsa de la escala de fortunas ${ }^{37}$; no obstante, para otros historiadores, aunque la fuente aparece deformada por esa correspondencia con una edad de la vida marcada por la vejez, no constituiría un problema para el análisis de la cultura material de las poblaciones de Antiguo Régimen, pues no importa tanto reconstruir una jerarquía como conocer o aproximarnos a los estados relativos de lo real y de intentar evaluar los cambios que se producen ${ }^{38}$. Para otros historiadores el argumento de achacar una débil representatividad social a los inventarios por tratarse de un acta específica de una edad alta de la vida, no se sostiene, puesto que conociendo un poco la demografía de Antiguo Régimen se comprende que muchos de los inventarios realizados pertenecían a personas que habían sido sorprendidas precozmente por la muerte, por lo que afectarían principalmente a adultos entre los 30-45 años ${ }^{39}$.

De la misma forma, aunque el volumen de los patrimonios estaba profundamente determinado por factores sociales y familiares, no se debe olvidar que la fase del ciclo de vida que atraviesa el núcleo doméstico también tiene una importante incidencia en el nivel de bienes inventariados ${ }^{40}$; por lo que, directamente relacionado con la posible distorsión que puede crear el hecho de que los inventarios abunden entre los grupos de edades avanzadas, también hay que destacar el inconveniente planteado por la abundancia de recuentos de bienes realizados en grupos domésticos en los que ha fallecido uno de los cónyuges, y ya se ha realizado una primera división de bienes entre los hijos, con lo que el volumen del patrimonio puede verse desvirtuado, y el número de objetos inventariados en este tipo de hogares puede reducirse de forma importante hasta el punto de contar únicamente con los artículos meramente imprescindibles. Así, debido a las limitaciones que presentan los inventarios de personas viudas, algunos investigadores, entre ellos varios historiadores españoles, han

en BAULANT, Micheline et alii (eds.): Inventaires aprés décès et ventes de meubles. Apports à une histoire de la vie économique et quotidienne XIVe-XIXe siècle, Louvain-la-Neuve, 1988, pp. 243-256.

36 CORNETTE, Jöel: «La Révolution des objets..., p. 480.

37 Cf. entre otros: Pardailhé-Galabrun, Annick: La naissance de l'intime..., p. 27; Roche, Daniel: Le peuple de París, París, 1981.

38 ROCHE, Daniel, ARNETTE, Rémy y ARDELliER, F., «Inventaires aprés décès Parísiens..., p. 232.

39 Cf. GARNOT, Benoît: La culture matérielle..., p. 138.

40 Acerca de la interrelación entre el ciclo de vida familiar y el volumen del patrimonio inventariado, Cf. para el caso canadiense Dessureault, Ch., «Fortune paysanne et cycle de vie. Le cas de la seigneurie de Saint-Hyacinthe (1795-1844)», en Histoire et Societés Rurales, (1997), nº 7, pp. 73-96. 
optado por descartar su análisis, para conseguir un mayor rigor metodológico en las muestras empleadas ${ }^{41}$. Otro problema que plantean los inventarios en cuanto a su representatividad, es el hecho de que éstos son predominantemente masculinos ${ }^{42}$. Ese menor número de inventarios de mujeres, lo cual puede ser debido a un mayor número de segundas nupcias de viudos, - prácticamente general en la demografía de Antiguo Régimen-, limita el análisis de algunos aspectos de la cultura material como el vestido femenino.

Para paliar la débil representatividad social que presentan los recuentos de bienes, en la utilización de este tipo de fuente notarial para el estudio de cualquier aspecto relativo a la cultura material de las sociedades de Antiguo Régimen, es necesario analizar períodos cronológicos amplios y vaciar muchas escrituras ${ }^{43}$, a fin de compensar las limitaciones que presenta la fuente.

Por lo que respecta al grado de fiabilidad de los inventarios, aunque este tipo de escrituras notariales parece ofrecer mayor margen de confianza que otras fuentes utilizadas para el estudio de la cultura material, como la iconografía o los testimonios literarios, sin embargo, no está exenta de reproches a su frabilidad, que es cuestionada en muchos casos. Los fraudes y eventuales subestimaciones y ocultaciones podían existir en un tipo de escritura notarial que por sus particularidades no era plenamente exhaustiva; por ejemplo, las actas de Acuerdos de la ciudad de Lugo llaman la atención sobre las ocultaciones propias de este tipo de escrituras: «...en los recuentos se cometen no pocas ocultaciones, por las justicias, con perjuicio de menores, $y$ en contemplación de las viudas y parientes.... ${ }^{44}$.

A las ocultaciones inherentes a toda fuente del período preestadístico, hay que añadir las posibles mermas y pérdidas de bienes, derivadas de las peculiaridades de este tipo de escrituras. Dado que los recuentos de bienes suelen realizarse fundamentalmente con ocasión de la muerte del cabeza de familia, en un momento propicio para que surjan tensiones familiares, por lo tanto es previsible que exista una voluntad de dispersar los bienes que el difunto ha dejado. Si a dicha voluntad añadimos la existencia de ciertas deficiencias consustanciales a la ejẹcución de una buena parte de los recuentos, comprenderemos la facilidad con la que una porción de los bienes reales no aparecerá consignada en los inventarios.

Normalmente, entre la fecha de óbito del difunto o difunta y la realización del recuento, suele transcurrir un intervalo de tiempo, que dependiendo de su

${ }^{41}$ Yun Casalilla, Bartolomé: «Inventarios..., p. 34; Ramos PalenCia, Fernando Carlos: «Una primera aproximación al consumo en el mundo rural castellano a través de los inventarios post-mortem: Palencia, 1750-1840", en TORRAS, Jaume y YUN CASALILLA, Bartolomé (dirs.): Consumo..., (pp. 107-101), p. 108; TORRA FERNÁNDEZ, Lídia: «Pautas de consumo textil en la Cataluña del Siglo XVIII. Una visión a partir de los inventarios post-mortem», en TORRAS, Jaume y YUN CASALILlA, Bartolomé (dirs.): Consumo..., (pp. 89-105), p. 92.

${ }^{42}$ Cf. Rozados Fernández, María Ángeles: Campo y ciudad..., p. 24; Baulant, Micheline, «Enquête..., p. 147.

${ }_{43}$ Roche, Daniel, ARNetTe, Rémy, y ARDellier, F.: «Inventaires aprés décès..., p. 233.

${ }^{44}$ AHPL, Ayunt./Act. Cap., Lib. 94. 
duración condiciona la integridad de los bienes que quedan en las casas tras la muerte de los cabezas de familia. Aunque habitualmente los inventarios se acostumbraban a realizar pocos días después del fallecimiento, y la tónica general era la rapidez de ejecución ${ }^{45}$, en ocasiones transcurrían períodos demasiado largos, de varios meses, lo que comprometía la garantía de que los bienes inventariados correspondiesen a la realidad; por ejemplo, en una muestra de más de medio millar de inventarios analizados en áreas rurales de la Galicia interior, el lapso de tiempo medio transcurrido entre la fecha de defunción del cabeza de familia o su cónyuge y la de verificación del inventario rondaba casi los 5 meses, existiendo algunos casos realmente extremos, en los que los bienes se inventariaban con varios años de retraso ${ }^{46}$. Si a esos amplios intervalos de tiempo transcurridos entre la fecha del óbito y la realización de los inventarios, añadimos el hecho de que una porción de ellos son confeccionados a lo largo de varios días ${ }^{47}$, y que, en ocasiones, en algunas zonas, los escribanos no acuden a las casas a hacer los recuentos, sino que los elaboran a partir de relaciones de bienes que les suministran los familiares del difunto/a, o que, además, en no pocos casos se tiende a ir posponiendo la confección del recuento a los últimos meses del año ${ }^{48}$; todo ello derivaría en inevitables mermas de los bienes fincables, ya sea por el reparto, el simple alimento de los miembros de la familia, o por gastos derivados de las distintas rentas y cargas de carácter señorial o fiscal que debían satisfacer; sin olvidar, los gravosos gastos de entierro, que merman los stocks de grano, ganado y otros productos, bien para hacer frente a los costes del entierro, o por el propio consumo de las exequias. Los gastos derivados del entierro hacían que en muchas ocasiones se tuvieran que vender algunos bienes del difunto/a, como cabezas de ganado, fibras textiles, provisiones de cereal o de carne (tocinos, jamones...), así como muebles ${ }^{49}$; además, en las pitanzas, honras u ofrendas se solían gastar importantes cantidades de pan, carne, vino y otros productos, lo que menoscababa el nivel de provisiones de las casas, reduciendo ostensiblemente el volumen de bienes inventariados ${ }^{50}$.

${ }^{45}$ Cf. para el caso gallego: PÉreZ GarCíA, José Manuel: «Aproximación al estudio de la penetración del maíz en Galicia», en EIRAS RoEl, Antonio et alii: La Historia Social..., (pp. 117-160), p. 125; RozAdos FernÁNDEZ, María Ángeles: Campo y ciudad..., p. 25.

${ }^{46}$ Cf. SOBRADO CORREA, Hortensio: Las tierras de Lugo..., p. 59. 4 (1728).

${ }^{47} \mathrm{Ej} .:$ «...por ser oy tan denoche suspendo el recuento hasta mañana...» AHPL, Protocolos, Leg. 445-

${ }^{48}$ Por ejemplo, en el área del interior gallego, de casi un millar de inventarios analizados, alrededor del $27 \%$ se habían realizado en los últimos meses del año. Cf. Sobrado CorreA, Hortensio: Las tierras de Lugo..., p. 60.

$49 \mathrm{Ej} .:$ «...una vaca y una juvenca vendidas para gastos de funerales...» (1710) AHPL, Protocolos, Leg. 404-9, fol. 18; «... treinta varas de estopa que se vendieron para pagar el funeral» (1704) AHPL, Protocolos, Leg. 386-7.

so Para el caso gallego Cf. PÉrez García, José Manuel, «Aproximación al estudio..., p. 126; SAAVEDRA FERNÁNDEZ, Pegerto, «Evolución de una agricultura de autoconsumo..., pp. 317-334.

Hispania, LXIII/3, núm. 215 (2003) 825-862 
En lo que se refiere a las omisiones, los inventarios presentan una serie de lagunas de información, que afectan en primer lugar a los datos personales del difunto/a, así como a los de las personas que integraban su familia, pues, si bien, en ocasiones especifican el número de hijos que han quedado tras la muerte de uno de los cónyuges, rara vez ofrecen información acerca del resto de los miembros que conviven en el agregado doméstico, por lo que no podemos conocer el número total de individuos que componen el hogar ${ }^{51}$; algo que resultaría interesante, por ejemplo, para calcular la relación entre el nivel de provisiones existentes en las casas y el número de potenciales consumidores, lo que permitiría aproximarnos, entre otras cosas, a las disponibilidades de cereal o carne por persona, o bien para hacernos una idea de la distribución del espacio doméstico y el nivel de mobiliario, en función del número de miembros de la familia, amén de posibilitar el análisis de aspectos tan interesantes como la evolución del tamaño y de la estructura familiar.

Los recuentos, además de ser poco explícitos respecto al número de individuos que componen la familia, suelen carecer de información referente a la edad, fechas de nacimiento y de matrimonio, y lugar de origen del difunto ${ }^{52}$, o acerca de su profesión; que en el campo, a diferencia de lo que ocurre en las ciudades, no suele aparecer especificada, aunque se sobreentienda que en el mundo rural de Antiguo Régimen los campesinos trabajadores de la tierra sean mayoritarios ${ }^{53}$. La falta de información sobre la actividad profesional de los difuntos dificulta el estudio de las actividades artesanales de la población, exigiendo búsquedas en otro tipo de documentación complementaria ${ }^{54}$. Otra omisión de información que suelen presentar este tipo de documentación notarial, y que plantea cierto problema metodológico, es la relativa a las valoraciones económicas de los bienes inventariados. El hecho de que en muchos casos la descripción de los bienes no vaya acompañada de su respectiva valoración monetaria, limita el estudio de aspectos tan interesantes como el consumo y las

51 La omisión de este tipo de información por parte de los inventarios ya había sido comentada en su tiempo por A. Eiras y R. Villares, Cf. Eiras Roel, Antonio y Villares PaZ, Ramón: «Información serial de inventarios post mortem: Area compostelana, 1675-1700», en EIRAS ROEL, Antonio et alii: Las Fuentes y los Métodos. 15 trabajos de Historia cuantitativa serial de Galicia, Santiago, 1977, p. 94

52 BAUlant, Micheline: «Typologie des inventaires..., p. 39; LenCiNA PÉREZ, Xavier: «Los inventarios post-mortem en el estudio de la cultura material y el consumo. Propuesta metodológica. Barcelona, siglo XVII», en TORRAS, J. y Yun CaSAlilla, Bartolomé (dirs.): Consumo..., (pp. 41-59), p. 45; a veces, en algunas zonas los inventarios ofrecen datos personales precisos sobre el difunto/a y su familia, como ocurre en el caso alemán Cf. BoRSCHEID, Peter: «Les inventaires Wurtembergeois..., pp. 205-229.

${ }^{53}$ Gran parte de los inventarios rurales gallegos no especifican la profesión del difunto Cf. RoZADOS FERNÁNDEZ, María Ángeles: Campo y ciudad..., p. 24.

${ }_{54}$ MOTTU-WEBWE, L.: «Inventaires de biens et Histoire des activités manufacturieres a Geneve (XVIe-XVIIle siècles). Un primer bilan», en BAULANT, Micheline et alii (eds.): Inventaires aprés décès et ventes de meubles..., pp. 233-242.

Hispania, LXIII/3, núm. 215 (2003) 825-862 
condiciones de vida de las poblaciones de Antiguo Régimen, aunque dicho problema ha sido satisfactoriamente resuelto en varias investigaciones a través de la utilización de la técnica del recuento del número de productos de cada tipo, consistente en el análisis de la mayor o menor abundancia en los inventarios de productos según categorías sociales y períodos, lo que ofrece interesantes pistas para aproximarnos a los cambios experimentados en el consumo en la larga duración ${ }^{55}$. A parte de las omisiones más o menos sistemáticas de información referente a los datos personales de los miembros de la familia, que como hemos comprobado, pueden limitar el análisis de determinados aspectos de interés, los inventarios presentan una serie de lagunas que dificultan su empleo para el estudio de distintos aspectos materiales del cuadro de vida, tales como la alimentación, la vivienda y el mobiliario doméstico, o la higiene y el vestido, entre otros.

El empleo de inventarios como fuente complementaria para el análisis de la alimentación tropieza con una serie de lagunas que limitan el estudio de este interesante aspecto de la cultura material. Los recuentos ofrecen una imagen deformada del régimen alimentario, pues realmente son omitidos casi siempre los géneros destinados al consumo corriente y sólo se registran los $s t o c k s{ }^{56}$, por lo que no son mencionadas más que las provisiones de alimentos susceptibles de conservarse (carnes saladas, legumbres secas...), mientras que los alimentos perecederos como la leche, la mantequilla, o los quesos, raramente aparecen registrados ${ }^{57}$; no se informa, pues, sobre los alimentos frescos, y apenas aparecen provisiones de legumbres frescas, o de carnes que no sean saladas o ahumadas. Además, los inventarios registran las provisiones de cereales, pero insólitamente hacen referencia al pan cocido en la hucha ${ }^{58}$.

De la misma forma, a través de los datos que nos ofrecen los recuentos, resulta muy difícil diferenciar la parte de los productos destinados al consumo familiar, al ganado o a la venta ${ }^{59}$, o los que se han de reservar para el pago de distintas cargas. Para analizar las reservas cerealeras que poseen las familias en distintos momentos del año, en muchos casos no contamos con datos referentes a los bienes raíces, ni a las superficies que explotan, o a las cantidades que han

5s Yun CASAlilla, Bartolomé: «La Historia económica por el lado de la demanda y el consumo: Unas reflexiones Generales», en TORRAS, Jaume y Yun CASAlilla, Bartolomé (dirs.): Consumo..., (pp. 9-23), p. 15

56 GARNOT, Benoît: La culture matérielle..., p. 146; FLANDRIN, Jean Louis: «L'alimentation paysanne en économie de subsistence», en FLANDRIN, Jean Louis y MONTANARI, Massimo (dirs): Histoire de l'alimentation, París, 1996 pp. 597 y ss.; acerca de esta limitación que presentan los inventarios, al registrar sólo el stock de productos, y no el consumo real. Cf. DE VRIES, Jan: «Between purchasing power..., pp. 102-103.

57 BAULANT, Micheline: «Enquête sur les inventaires après décès autour de Meaux aux XVII et XVIIIe siècles", en VAN DeR WOUde, A.D. y SchuURman, Anton (eds.): Probate inventoires..., (pp. 141-156), p. 146; WARO-DESJARDINS, François: La vie quotidienne..., p. 128; FlaNDRIN, Jean Louis: «L'alimentation..., p. 613.

58 BaUlant, Micheline: «Typologie des inventaires..., p. 39.

59 WARO-DESJARDINS, François: La vie quotidienne..., p. 128. 
de pagar en concepto de diezmos, rentas u otras cargas y pensiones, lo que dificulta el análisis de aspectos tan interesantes como las disponibilidades de producción agrícola, y las tasas de consumo de cereal por familia, o por persona ${ }^{60}$.

La utilización de los inventarios como fuente complementaria para el estudio de la vivienda, también presenta ciertas limitaciones, ya que éstos suelen ofrecer descripciones muy vagas, y poco detalladas sobre la arquitectura y apariencia exterior de las casas, por lo que el análisis de aspectos como la superficie, número de pisos, estructura, y materiales empleados en la construcción de las viviendas de Antiguo Régimen, o acerca de la situación y valor catastral, no siempre es posible a partir del empleo de esta fuente notarial ${ }^{61}$. Asimismo, aunque los inventarios sí nos permiten penetrar en los hogares de la época, no siempre proporcionan datos sobre la distribución del interior de las viviendas, pues en muchas ocasiones los recuentos son hechos sin ningún tipo de orden, y no aparece referencia alguna a las distintas dependencias de las casas, por lo que, análisis tan interesantes como la evolución del espacio doméstico, y la especialización de las estancias a través del período moderno, pueden verse limitados por las lagunas que presentan algunos inventarios post-mortem. El hecho de que la curiosidad de los escribanos o tasadores que hacen los recuentos de bienes no se aproxime ni por asomo a la del historiador, lleva a que el aspecto exterior de las casas o la disposición interna de las viviendas apenas sean anotados, y que todos los objetos existentes en los hogares no sean descritos, en particular aquellos que no presenten un valor suficiente ${ }^{62}$. Por lo tanto, los inventarios no pueden ser considerados como una fuente exhaustiva en lo que concierne al estudio de la vivienda, así como al registro de todos los objetos del hogar, pues suelen existir omisiones de objetos domésticos y de uso corriente, de muebles, de ropa, de dinero líquido, de joyas, etc.; objetos en ocasiones insignificantes en valor económico, pero significativos para el estudio de la cultura material ${ }^{63}$.

Si bien los inventarios son un tipo de fuente rica en información, que nos describe el mobiliario, sin embargo, dichas escrituras no constituyen más que un puesto de observación imperfecto de los muebles que contienen los interiores domésticos en el período moderno, puesto que al inventariarse los bienes en un momento puntual y determinado del ciclo de vida familiar ${ }^{64}$, pueden existir omisiones de algunos muebles que han sido donados en dote, o por medio de una división hereditaria; sin olvidar, el hecho de que algunos objetos fáciles de

${ }^{60}$ Cf. Eiras Roel, Antonio y Villares Paz, Ramón: «Información serial..., p. 94; Villares PAZ, Ramón: Los inventarios..., p. 9.

61 PARDAIlHÉ-Galabrun, Annick: La naissance de l'intime..., p. 30.

${ }^{62}$ CORNETTE, Joël: «La Révolution des objets..., p. 480.

${ }^{63}$ LeNCINA PÉREZ, Xavier: «Los inventarios post-mortem..., p. 45.

${ }_{64}$ Para algunos autores, la redacción de los inventarios en diferentes estados del ciclo de vida de los hogares constituye, una debilidad del documento para reconstruir las estructuras sociales. Cf. OUELLET, F.: «La mentalité et l'outillage économique du paysan canadien en 1760: à propos d'un document sur l'encan», en Bulletin de recherches historiques, n 62 (janvier-mars, 1956), pp. 131-139. 
vender hayan desaparecido antes de inventariar los bienes, se hayan dividido amistosamente entre los miembros de la familia, o bien fueran omitidos a causa de que el escribano no les haya reconocido valor de mercado. Además, los inventarios presentan una gran limitación en cuanto a las descripciones del estilo de los muebles, sus dimensiones, sus formas, así como su estado de conservación, utilizando calificativos muy poco precisos como los de «viejo», «usado», en «buen estado", etc. ${ }^{65}$. El escaso detalle en las descripciones de los muebles inventariados puede dar lugar a confusiones, pues un mismo nombre puede designar muebles diferentes, muy variados según las regiones y las épocas, con lo que se corre el riesgo de llegar a confusiones incluso en el seno de una misma lengua ${ }^{66}$.

Por lo que respecta al estudio del vestido, aunque los inventarios constituyen una fuente útil y rica ${ }^{67}$, presentan ciertas limitaciones, pues acostumbran a mostrar una clara omisión de ropas, tanto de los difuntos como de sus cónyuges $^{68}$. En este tipo de escrituras son más abundantes las menciones a ropa de cama y de mesa, que a ropa de vestir ${ }^{69}$. Son pocos los recuentos que incluyen el registro de guardarropas ${ }^{70}$, y entre ellos es difícil encontrar descripciones detalladas de la indumentaria tanto masculina como femenina. En algunas ocasiones el mal estado, o el escaso valor de la ropa del difunto/a, la reventa de ésta, o la donación de parte de ella o de su totalidad a los pobres ${ }^{71}$, es la causa directa de que no sea inventariada, sin embargo, en muchos casos en la sociedad rural si el difunto sólo contaba con una muda y había sido enterrado con su ropa, difícilmente habría alguna prenda que recontar. A veces, aunque los inventarios hacen referencia a prendas de ropa, sin embargo las descripciones brillan por su ausencia, y el escribano se limita a inventariar «un vestido», que en el mejor de los casos, detalla si es ordinario, de cada día, o bien de fiesta, sin especificar las prendas que lo componen ${ }^{72}$, lo que limita el análisis de aspectos tan interesantes como la tipología del vestido, o los tejidos y colores predominantes.

65 PÉRET, Jacques: «Les meubles ruraux..., p. 488.

66 BAULANT, Micheline: «Necessite de vivre et besoin de paraitre. Les inventaires et la vie quotidienne», en BAULANT, Micheline et alii: Inventaires aprés décès..., pp. 9-17.

${ }^{67}$ SARTI, Raffaella: Vita di casa. Abitare, mangiare, vestire nell'Europa moderna, Roma-Bari, 1999, p. 238.

68 BAULANT, Micheline: «Typologie..., p. 39.

69 Baulant, Micheline y VArI, Stéphane: «Du fil à l'armoire. Production et consommation du linge à Meaux et dans ses campagnes XVIIe-XVIIIe siècles», en Etbnologie française, t. $16, \mathrm{n}^{\circ} 3$, Juillet-Sept., (1986), pp. 273-280.

70 Por ejemplo en el caso de la comarca de Santiago de Compostela, entre los inventarios analizados por Ramón Villares, entre $1675-1715$, alrededor del $56 \%$ omiten la ropa masculina, y el $65 \%$ no hacen referencia a ropa femenina. Cf. VIllares PAZ, Ramón: Los inventarios..., p. 78.

${ }^{71} \mathrm{Ej} .:$ «y quanto a la mas ropa de dicho difunto, de su borden se destribuio a pobres» AHPL, Protocolos, Leg. 507-5, fol. 143.

72 Ej.: (7-III-1763) Invent. de Agustín González, vº de Billan, concejo de Navia (Lugo): «un vestido ordinario..." AHPL, Protocolos, Leg. 1476/3; (16-XI-1760) Invent. de Juan Alvarez, vº de Trebello (Lugo): «un vestido usado de cada día...» AHPL, Protocolos, Leg. 1476/1. 
No obstante, las omisiones de información más claras de los inventarios acerca del vestido, tienen lugar en el caso de los menores. En lo que respecta a la indumentaria infantil, los recuentos de bienes ofrecen un silencio casi absoluto, siendo muy raras las menciones a las ropas de niños ${ }^{73}$, y en todo caso aparecen algunas referencias a piezas de tela destinadas a vestir a los hijos ${ }^{74}$; así por ejemplo, en el ámbito francés, N. Pellegrin en su estudio sobre el vestido en el área de Poitou sólo encuentra 6 inventarios con menciones a ropas de niños ${ }^{75}$, y en algunos inventarios de Magny-en-Vexin aparecen referencias a prendas de niños, vestidos sobre el mismo modelo que el de sus padres ${ }^{76}$. En los inventarios de nuestro país la ausencia de información sobre la ropa de los más pequeños, también es la tónica general, y son pocos los documentos que detallan alguna prenda infantili7.

Todos los especialistas que han utilizado y utilizan los inventarios postmorten para el estudio de algún apartado de la Historia social son conscientes de sus lagunas, así como del hecho de que conviene utilizarlos contentándose con la consecución de estimaciones en lugar de buscar una precisión engañosa. Debido a toda esta suerte de omisiones que presenta este tipo de documentación, es sólo con la explotación de un gran número de escrituras como se puede paliar una parte de las lagunas que presenta cada acta de recuento ${ }^{78}$. Además, los inventarios, no son una fuente que pueda ser empleada aislada, sino que es recomendable que su información sea complementada con la que ofrecen otras fuentes diversas que puedan suministrar información sobre las mismas personas o fortunas inventariadas ${ }^{79}$.

Para muchos autores, hasta la utilización serializada de las escrituras de recuentos de bienes, el uso de esta fuente para el estudio de la cultura material de las poblaciones del período moderno, no iba más allá de lo puramente anecdótico, y prácticamente se limitaba a la presentación de detalles de carácter pintores $\mathrm{Co}^{80}$. Sólo a partir del desarrollo de métodos cuantitativos en la explotación sistemática de los inventarios, se llegaría a análisis en profundidad, conseguidos merced al ensayo de una metodología adecuada a la explotación masiva de esta documentación notarial, que en determinados casos incluiría también el

73 Waro-Desjardins, François: opus cit., pp. 163 y ss.; BaUlant, Micheline: «Ênquete...; JURGENS, Madeleine, Inventaires après décès. 2 vols. T. I (1483-1547), París, 1982, p. 22.

${ }^{74}$ Cf. Rozados FernándeZ, María Ángeles: opus cit., p. 111.

75 Pellegrin, Nicole: «L' habillement rural en Poitou..., p. 479.

76 WARO-DESJARDINS, François: La vie quotienne..., pp. 230 y ss.

77 Rozados Fernández, María Ángeles: Campo y Ciudad..., p. 111; TORRA FernÁNDEZ, Lídia: «Pautas de consumo textil..., (pp. 89-105), p. 92.

78 GARNOT, Benoît: La culture matérielle..., pp. 138 y ss.; JACQUART, Jean: «L' utilisation des inventaires aprés décès villageois..., p. 188.

79 EIRAS Roel, Antonio y VILlares Paz, Ramón: «Información serial..., pp. 93-94; Pereira IGLESIAS, José Luis y RODRíGUEZ CANCHO, Miguel: «Inventarios post-mortem y riqueza campesina en Extremadura. Aproximación metodológica», en Norba, IV, (1983), (pp. 351-359), p. 354.

${ }^{80}$ JACQUART, Jean, «L' utilisation..., p. 187.

Hispania, LXIII/3, núm. 215 (2003) 825-862 
uso del ordenador ${ }^{81}$. No obstante, y si bien la informática aplicada a la explotación serial de los inventarios, puede facilitar la labor del historiador, permitiendo el estudio de grandes masas documentales, existen voces a favor de la utilización de métodos más artesanales ${ }^{82}$, pues éstos presentan una serie de ventajas sobre los fríos y anónimos métodos estadísticos, ya que permiten un análisis preciso, individualizado de cada caso, ajustándose más a la realidad, que no siempre es estadística ${ }^{83}$, y permitiendo estudiar tanto a los individuos como a los grupos sociales de forma más personalizada.

En todo caso, ya sea a través de sofisticados métodos informáticos, o por medio de métodos más artesanales, el estudio serial de los inventarios posibilita una arqueología de los objetos cotidianos, que satisfacen una serie de necesidades inmediatas y básicas de la vida cotidiana de las gentes.(alojarse, alimentarse, vestirse), así como la que responde a una doble voluntad de confort y de ostentación (elementos decorativos, joyas) ${ }^{84}$. No importa que objeto, desde el más ordinario que se pueda encontrar en el inventario de una vivienda, éste encierra una cultura ${ }^{85}$, permitiéndonos una aproximación al peso real de lo cotidiano, así como a las condiciones materiales de vida. Por lo tanto, la utilización sistemática de esta fuente notarial permite a los historiadores renovar nuestros conocimientos en diversos dominios de la vida cotidiana de las poblaciones del pasado, tales como la Historia del hábitat, del vestido, de la alimentación, o de la difusión de distintas prácticas sociales y culturales.

\section{LA ALIMENTACIÓN}

La escasez de fuentes y la parquedad de las informaciones que éstas proporcionan, ha hecho que tradicionalmente, la historiografía modernista centrada en el estudio de la alimentación haya prestado una mayor atención al análisis del consumo urbano ${ }^{86}$, así como al régimen alimentario de los sectores privile-

81 BAULANT, Micheline: «L'analyse par ordinateur..., pp. 197-203; BAULANT, Micheline et alii: "Problematique et méthode communes aux corpus présentés par les chercheurs de L'E.H.E.S.S. de París. Bourgogne (XIVe-XVe siècles)- Brie (XVIIe-XVIIIe siècles)- Crete (fin XVIIe-XVIIIe siècles)", en VAN Der WOUde, A.D. y SCHuURman, Anton (eds.): Probate inventoires...; (pp. 115-126), p. 121; HÖHER, P.: «Domestic types in a southern Germam town (16301899) an attempt at definition using automatic classification methods», en BAUL.ANT, Micheline, et alii (eds.): Inventaires aprés décès et ventes de meubles..., pp. 153-170.

82 Cf. PARDAilhÉ-Galabrun, Annick: La naissance de l'intime..., opus cit.

83 JACQUART, Jean: «L'utilisation..., p. 191.

${ }_{84}$ BOURQUIN, Laurent: «Les objets de la vie quotidienne dans la première moitié du XVIe siècle a travers cent inventaires après décès Parísiens", en Revue d'Histoire Moderne et contemporaine, XXXVI, 1989, (pp. 465-475), p. 464.

85 ROCHE, Daniel: Histoire des choses banales. Naissance de la consommation dans les sociétés traditionelles (XVIIe-XIXe siècles), París, 1997, p. 13.

86 Espadas Burgos, Manuel y AsCensión Burgos, M.: «Abastecimiento de Madrid en el S. XVI», en Madrid en el S. XVI. Instituto de Estudios Madrileños. Madrid, 1961; PalaCiO ATARD, Vi- 
giados de la sociedad, o del de medios sociales minoritarios como el de los marinos, soldados, prisioneros, guardias, o bien del consumo hospitalario y de diversas instituciones (colegios mayores, conventos) ${ }^{87}$, cuya documentación (contabilidades de servicios de la armada, de hospitales, etc.) permite cuantificar el consumo alimentario ${ }^{88}$. Y aunque, también se ha analizado el consumo de jornaleros o criados agrícolas, sin embargo, el estudio de la alimentación campesina ha quedado relegado a simples aproximaciones, pues normalmente no existen libros de cuentas, memorias o contabilidades que nos expliquen lo que consumía un campesino ordinariamente, más allá de testimonios indirectos, de tipo literario, o bien algunas anotaciones de dietistas sobre las actitudes alimentarias regionales, o testimonios de los agrónomos ${ }^{89}$.

Las verdaderas dificultades en el estudio de la alimentación campesina surgen cuando tratamos de pasar de lo cualitativo a lo cuantitativo, en el momento en el que se trata de ensayar cifras de consumo anual de una familia o la

cente: «Algo más sobre el abastecimiento de Madrid en el siglo XVIII», en Villes de l'Europe méditerranéenne et de l'Europe Occidentale, Annales de la Faculté des Lettres et Sciences Humaines, nº 9-10 (1969), (pp. 253-275), p. 253; del mismo autor: «Problemas de abastecimiento en Madrid a finales del S. XVIII", en Villes..., pp. 279-288; y La alimentación de Madrid en el siglo XVIII y otros estudios madrileños, Madrid, 1998; CASTRO, C. (de): El pan de Madrid. El abasto de las ciudades españolas del Antiguo Régimen. Madrid, 1987; HERNÁNDEZ ESTEVE, Esteban: Noticia del abastecimiento de carne en la ciudad de Burgos (1536-1537). Libro Mayor del obligado de las carnicerías. Madrid, 1992.

87 ENRÍQUeZ MORALES, María José: Sondeos sobre alimentación y consumo bospitalario. El Real Hospital de Santiago, Santiago, 1974; EIRAS RoEl, Antonio y EnRíQuez MORALES, María José: «La Consommation alimentaire d'Ancien Régime: les collèges de Saint-Jacques de Compostelle», en Dossier Histoire de la Consommation, Annales, XXX, 2-3 (1975), pp. 454-464; ); VICENT, Bernard: «Consommation alimentaire en andalousie Orientale: Les achats de 1'Hôpital Royal de Guadix, 1581-1582», en Dossier..., pp. 445-453; BENNASSAR, Bartolomé y GOY, Joseph: «Contribution à l'histoire de la consommation alimentaire du XIVe au XIX siècle», en Dossier Histoire de la Consommation (Annales, XXX, 2-3, 1975, 409-411; PIUZ, Anne-Marie: «L'alimentation hospitalière à Genève» en Mélanges Richard Gascon, II, Lyon (1980), pp. 167-185; CroIX, Alain: La Bretagne aux 16 et 17 e siècles. La vie, la mort, la foi. 2 vols., París, 1981, pp. 813 y ss.

${ }^{8}$ Cf. PAlacio ATARD, Vicente: «Notas acerca de la Historia de la alimentación», en Los Españoles de la Ilustración. Madrid, 1964, pp. 287-307; BENNASSAR, Bartolomé y GOY, Joseph: "Contribution a l'Histoire de la consommation alimentaire du XIVe au XIX siècle», en Annales, (1975),(pp. 402-430), p. 415; FLANDRIN, Jean Louis: «Historia de la alimentación: por una ampliación de las perspectivas», en Manuscrits, 6, (1987), pp. 7-29; EIRAS ROEL, Antonio: «La Historia de la alimentación en la España Moderna: resultados y problemas», en Obradoiro de Historia Moderna, 2 (1993), pp. 35-64.

89 FLANDRIN, Jean Louis: «L'alimentation paysanne..., p. 598; BONNIN, Bernard: "L'alimentation dans les milieux populaires en France au XVIIe siècle: essai de mise au point», en Marseille, $\mathrm{n}^{\circ} 109$, 2eme. Trimestre, (1977), La qualité de la vie au XVIIe siècle. (7e. Colloque de Marseille), pp. 75-81. Acerca del escaso número de trabajos sobre la alimentación en el mundo rural para el caso de la historiografía modernista gallega, Cf. SOBRADO CORREA, Hortensio, «El sustento y la morada: aspectos de las condiciones materiales de vida en la Galicia rural de la Edad Moderna", en FERnÁndez CORTIZO, Camilo et alii: Universitas. Homenaje a Antonio Eiras Roel, Santiago, 2002, t. I, pp. $425-438$.

Hispania, LXIII/3, núm. 215 (2003) 825-862 
ración cotidiana, ya que para este tipo de cálculos la mayor parte de la documentación que ofrece información acerca de la alimentación campesina resulta inutilizable, o cuanto menos muy limitada. Aunque algunas fuentes documentales de carácter indirecto, bien de origen administrativo, notarial, eclesiástico o incluso judicial, como las memorias de intendentes, las encuestas fiscales, los contratos de venta de cosechas, reconocimientos de derechos señoriales, testamentos, contratos de matrimonio, etc., pueden ofrecernos alguna información cualitativa sobre el consumo campesino, no permiten, sin embargo, una cuantificación precisa. Lo mismo ocurre con los inventarios, pues, aunque en teoría podría tratarse de una fuente interesante para el estudio de este aspecto, ya que hace referencia al stock de cereales y de otros productos alimentarios existentes en las casas, sin embargo, en la práctica, la cuantificación del consumo de cereales o de otro tipo de productos por familia o persona, resulta limitado por las propias omisiones de información que presenta la fuente. Debido al desconocimiento del número de componentes de la familia, o de las cantidades exactas que se han de descontar de la producción para el pago de rentas, pensiones, diezmos y otras cargas, resulta muy difícil calcular de forma precisa el consumo familiar o por persona ${ }^{90}$.

Dado que en el mundo rural del período moderno predominaba una economía de subsistencia, donde lo principal de la producción era consumido por el que lo producía, sin pasar por el mercado, resulta muy difícil cuantificar el consumo. Quizás la fuente más susceptible de ser cuantificada para el estudio del régimen alimentario de la población rural de Antiguo Régimen sea la de las pensiones alimentarias hechas por el heredero de una explotación a sus padres cuando éstos le pasan la dirección antes de la muerte ${ }^{91}$. Se trata de una fuente utilizada en Francia, que brinda información sobre el régimen de sus beneficiarios, dando una imagen bastante completa y menos ambigua que la que ofrecen los inventarios, permitiendo el cálculo de las raciones de forma más precisa ${ }^{92}$.

Pese a que para el estudio de la alimentación de la población de Antiguo Régimen, la utilización de los inventarios post-mortem resulta insuficiente, dadas sus limitaciones, no obstante, constituyen una fuente complementaria de gran valor para la aproximación a la dieta campesina ${ }^{93}$. Los recuentos de bienes, jun-

${ }_{90}$ Por ejemplo, en su aproximación al consumo de cereales de la población del área compostelana en el último cuarto del s. XVII, Antonio Eiras y Ramón Villares se encuentran con que sólo el $40 \%$ de los inventarios analizados permiten conocer el número de miembros de la familia. Cf. EIRAS ROEL, Antonio y VILlares Paz, Ramón: «Información serial..., p. 101.

${ }^{11}$ FLANDRIN, Jean Louis: opus cit.; BONNIN, Bernard: «L'alimentation dans les milieux populaires..., pp. 75-81.

${ }^{2}$ Cf. BOEHLER, Jean Michel: Une Société rurạle en milieu rbénan: la paysannarie de la plaine d'Alsace (1648-1789), 2a. Ed., Strásbourg, 1995, p. 1733.

${ }_{93}$ Sobre la utilidad de las fuentes notariales para el studio de la alimentación, Cfr. RIERA i MELIS, A.: "Documentació notarial i historia de l'alimentación, Estudis d'Història Agrària. Alimentaciò i Història, 13, 2000, pp. 17-43. 
to con el apoyo de otras fuentes documentales, hacen posible al historiador indagar acerca de cómo estaban nutridos los sectores populares de la sociedad, permitiendo constatar cuales eran los alimentos de base, los productos más corrientes en las mesas campesinas y en que medida su ración cotidiana era más o menos abundante, variada, o en todo caso suficiente para desarrollar una vida cotidiana normal.

La información contenida en los inventarios ha contribuido a corroborar como la alimentación campesina de Antiguo Régimen presentaba unas acusadas diferencias comarcales, caracterizándose por su gran irregularidad a lo largo del año ${ }^{94}$, así como por su monotonía y escasa diversificación, con un gran peso de los cereales como alimentos de base. El predominio del pan en el régimen alimentario popular era muy destacado, en un momento en que en la Europa de la época, los cereales y a veces otras harinas, constituían alrededor del $80 \%$ de la ración calórica ${ }^{95}$. A pesar de una clara constatación de la primacía de los cereales en la dieta campesina, los investigadores se encuentran con grandes dificultades para conocer la cantidad de pan consumido, si bien se han hecho algunas aproximaciones al consumo familiar e individual. Por ejemplo, en Galicia, atendiendo a análisis realizados en las comarcas de Xallas, la Ulla y el Salnés, en la zona de Santiago, o en áreas de la Galicia oriental, como el interior lucense, se han calculado disponibilidades medias de pan por persona y día que podían oscilar entre los 500 y los 800 gramos, aunque en algunos casos se lleguen a alcanzar o superar los 900 gramos $^{96}$. Estas disponibilidades de consumo de cereal estimadas para la Galicia de Antiguo Régimen, son menores a las detectadas en varias regiones de Francia, en donde se observan medias próximas al Kilo de pan por persona y día, en áreas rurales como el Languedoc, el Beauvais, o incluso superiores como ocurre en Auvernia, donde sus habitantes eran grandes consumidores de pan, y se considera que un adulto consumía del orden de 1.300 gramos al día ${ }^{97}$.

Los inventarios también han permitido constatar la importancia que tenían en la dieta campesina otros productos complementarios del pan, pero que en determinadas zonas de Europa se convierten en auténticos alimentos de base, como ocurre en el caso de las castañas. En zonas de Francia, como la Bretaña o los Pirineos este fruto constituía un alimento complementario a los cereales,

${ }^{4}$ Cf. SAAvedra Fernánddez, Pegerto: La vida cotidiana en la Galicia del Antiguo Régimen, Barcelona, 1994, pp. 128 y ss.

95 FLANDRIN, Jean Louis: «L'alimentation paysanne..., p. 603.

96 Cf. Barreiro Mallón, Baudilio: La Jurisdicción de Xallas..., pp. 301-305; ReY Castelao, Ofelia: Aproximación a la Historia rural..., p. 111; PÉreZ García, José Manuel: Un modelo de sociedad rural..., p. 384; EIRAS ROEL, Antonio y VILLARES.PAZ, Ramón: Información serial..., p. 104; SOBRADO CORREA, Hortensio «Aproximación al consumo alimentario en el área rural gallega: el interior lucense (siglos XVII-XIX)», Obradoiro de Historia Moderna; n 3; (1994), (pp. 87-110), p. 90.

97 Cf. Le Roy LAdURIE, Emmanuel: Les paysans du Languedoc, París, 1960, p. 176; GOUBERT, Pierre: Beauvais..., p. 105; PoITRINEAU, Abel: La vie rurale en Base Auvergne au XVIIle siècle, París, 1965. 
pero en otras como el Limousin, Auvernia, Savoya o el Perigord, la castaña suponía un verdadero alimento de base, que en muchos casos suplía al pan ${ }^{98}$; al igual que ocurría en determinadas áreas de Galicia, como en las parroquias vitícolas de Ourense y del sur de Lugo, en las que los campesinos compensaban la escasez de pan con el consumo de castañas ${ }^{99}$. Los inventarios post-mortem de estas zonas suelen contar con existencias de castañas que, bien, verdes o secas, según la estación, se almacenaban en las casas campesinas, para consumir a lo largo del año ${ }^{100}$.

Por lo que respecta a la carne, los recuentos de bienes dan la imagen de que ésta era consumida en cantidades limitadas en el campo. Dado que los inventarios no recogen existencias de carnes frescas, y que sólo hacen referencia a carnes saladas o en cecina, limitan bastante el análisis de este tipo de consumo. La carne de cerdo era la más presente en los inventarios, mientras que el resto de carnes era rara o inexistente, salvo en casas de sectores privilegiados. Las provisiones de tocinos, untos y sebo en muchos hogares campesinos, así como de algunos jamones en casas pudientes, muestran como el cerdo era el animal más democrático entre la sociedad campesina, y su carne contaba con una destacada presencia en sus mesas; asimismo, en algunas casas también aparecen porciones de cecina, normalmente pertenecientes a vacas viejas sacrificadas una vez que ya no sirven para los trabajos agrícolas ${ }^{101}$. La falta de provisiones de carne de ganado ovino-caprino, o de otro tipo como pueden ser aves de corral, no quiere decir que los campesinos no consumiesen alguna vez este tipo de carnes, ya que efectivamente, contaban en sus explotaciones con animales de estas especies; sin embargo, este tipo de carnes no acostumbraban a formar parte de la dieta diaria de las clases populares, y solía reservarse para la venta, el pago de rentas, o bien para el consumo en momentos especiales, de fiesta.

Algo que resulta paradójico, es que en los inventarios aparezcan gallinas, y sin embargo nunca existan menciones a la existencia de huevos, o que reflejen en muchas zonas abundantes cabañas de ganado vacuno, o de ovino-caprino, y no aparezcan provisiones de leche, manteca ni quesos ${ }^{102}$, cuando varios autores hablan de la leche y sus derivados como parte importante de la dieta campesina en la Europa del período moderno ${ }^{103}$. Tampoco hay menciones en los inventarios a la existencia de conejos domésticos en las casas, un tipo de práctica que

98 Bruneton-Governatori, A.: Le pain de bois. Ethnohistoire de la châtagne et du châtaignier. Toulouse, 1984.

99 SAAVEdRA Fernández, Pegerto: La vida cotidiana..., p. 141.

100 SOBRAdo CORREA, Hottensio: «Aproximación al consumo..., p. 102.

101 SOBRADO CORREA, Hortensio: opus cit., p. 94.

102 En el caso gallego esta omisión de información por parte de los inventarios es muy corriente, incluso en algunas zonas que contaban con cierto prestigio como fabricantes de quesos. Cf. ROZADOS FERnÁnDEZ, María Ángeles: opus cit., p. 67; SOBRADO CORREA, Hortensio: opus cit., p. 103.

103 BraUdel, Fernand: Civilisation materielle et Capitalisme, París, 1967, p. 153; SLICHER VAN BATH, B.H.: Storia agraria dell'Europa occidentale. 500-1850, Torino, 1972, p. 399.

Hispania, LXIII/3, núm. 215 (2003) 825-862 
no debió de prosperar hasta finalizado el Antiguo Régimen, y que parece que se encontró con oposiciones, como observa François Waro, quien encuentra en Magny, varias ordenanzas prohibiendo la cría del conejo en el siglo XVIII ${ }^{104}$.

Asimismo, en muchos casos no se suelen citar en los inventarios verduras, legumbres u otras especies vegetales, presentes, sin embargo, en las huertas campesinas, incluso en zonas en las que se sabe por otras fuentes, que existía una destacada producción de este tipo de productos, tal como ocurría en algunas áreas de Galicia, como en los alrededores de Santiago de Compostela, en donde no aparecen menciones a los grelos, cuando este tipo de verdura gozaba de gran estimación en la zona ${ }^{105}$.

Los inventarios también nos han ofrecido a los historiadores algunas pistas sobre el consumo de nuevos productos y su difusión entre la sociedad de la época, lo que ha permitido el seguimiento de la introducción y evolución de nuevas plantas como el maíz y la patata ${ }^{106}$, o de productos coloniales como el café o el chocolate; en contra de lo que ocurre en el caso del maíz y las patatas, en el que suelen aparecer en las casas reservas de estos artículos, las menciones a existencias de café o cacao son más bien nulas, sin embargo, a veces la presencia en los recuentos de utensilios empleados para la elaboración de estas nuevas bebidas, como chocolateras, cafeteras, o tazas para el café, ofrecen pequeñas pistas para aproximarnos al consumo de este tipo de productos y a la introducción de nuevos hábitos en el seno de las sociedades de Antiguo Régimen ${ }^{107}$.

\section{LA VIVIENDA Y EL MOBILIARIO DOMÉSTICO}

El empleo de los inventarios, a pesar de las limitaciones ya señaladas, ha permitido al historiador una aproximación a las características de la vivienda y del mobiliario doméstico, así como a sus transformaciones a lo largo del período moderno, lo que ha ofrecido interesantes pistas acerca del nivel y estilo de vida familiar. Debido a las escasas noticias que ofrecen muchos recuentos de bienes sobre la estructura externa de las casas, los estudiosos de la vivienda han tenido que echar mano de fuentes complementarias como las fuentes fiscales

\footnotetext{
104 WARO-DESJARDINS, François: La vie quotidienne..., p. 133; Vid. también: GouBERT, Pierre: Les paysans français..., p. 112.

105 RoZAdOS FernándeZ, María Ángeles: opus cit., p. 67.

106 Para el caso gallego Cf. PÉREZ GARCíA, José Manuel: «Aproximación al estudio de la penetración del maíz...; SAAvedra FernándeZ, Pegerto: Economía, política..., pp. 181 y ss.; Sobrado CORREA, Hortensio: Las tierras de Lugo..., p. 255.

107 Ramos Palencia, Fernando Carlos: «Una primera aproximación..., p. 123; LeNCINA PÉREZ, Xavier: «Los inventarios..., p. 56. Sobre esta cuestión, aunque utilizando otro tipo de fuentes, Cfr. PÉREZ SAMPER, María de los Ángeles: «Chocolate, té y café: sociedad, cultura y alimentación en la España del siglo XVIII», en Ferrer Benimeli, José A., (Dir.): El Conde de Aranda y su tiempo, I, Zaragoza, 2000, pp. 157-221.
}

Hispania, LXIII/3, núm. 215 (2003) 825-862 
(catastros...), fuentes judiciales, cuentas privadas y públicas, dossieres consagrados a la construcción o a la restauración de edificios, contratos de obra, o bien fuentes literarias o libros de viajes que reflejen descripciones de la época, entre otras ${ }^{108}$. Sin olvidar los planos, que junto con la iconografía (grabados, pinturas...) constituyen una valiosa fuente que permite al historiador observar la evolución de la ciudad, los cambios experimentados en la estructura urbana, en los espacios urbanos y en los edificios públicos ${ }^{109}$.

A pesar de las limitaciones que presentan los recuentos de bienes para el estudio de la vivienda de Antiguo Régimen, y de la necesidad de emplear fuentes complementarias, no obstante, los datos que aportan dichas escrituras notariales han contribuido al análisis de la estructura externa de las viviendas rurales y urbanas, así como a la superficie, número de pisos y materiales empleados en su construcción, lo que ha permitido una aproximación a la tipología de la vivienda, y de sus cambios a lo largo del período moderno, directamente relacionados con las transformaciones socioeconómicas experimentadas ${ }^{110}$. Precisamente, la encuesta colectiva realizada en los años 70 , bajo la dirección de Pierre Chaunu ( $L e$ Bâtiment enquête d'bistoire Économique...), constituyó, en su momento, un excelente ejemplo para observar el papel de los cambios de los edificios a través de la Edad Moderna, en relación con la evolución de la economía. Las contribuciones de H. Neveux sobre las viviendas en Cambrai, o de J. P. Bardet, acerca de las casas de Rouen, así como las de G. Désert y P. Chaunu, entre otras, contribuyeron al análisis de las transformaciones de la vivienda de Antiguo Régimen ${ }^{111}$.

Será en el ámbito del interior de las viviendas, tanto urbanas como rurales, en el que los inventarios manifiesten sus mayores aportaciones en información,

108 NeVEUX, Hugues: «Recherches sur la construction et l'entretien des Maisons a Cambrai de la fin du XIVe siècle au début du XVIIIe», en BARDET, Jean Pierre et alii: Le Bâtiment enquête d'bistoire Économique, XIVe-XIXe siècles. T. I: Maisons rurales et urbaines dans. la France traditionelle, París, 1971, pp. 123-187.

109 BROISE, Henri: «Les maisons d'habitation à Rome aux XVe et XVIe siècles: Les leçons de la Documentation Graphique», en VIGUEUR, Jean-Claude Marie (ed.): D'une ville à l'autre: structures matérielles et organisation de l'Espace dans les villes européennes (XIIIe-XVIe siècles), Actes du colloque organisé par l'École française de Rome avec le concours de l'université de Rome (Rome, 1-4 décembre 1986), Rome, 1989, pp. 609-629; BARDET, Jean Pierre: Rouen aux XVIIe et XVIIle siècles. Les mutations d'un espace social, 2 vols., París, 1983; TuRrel, D.: Le comméntaire de documents iconographiques en bistoire, París, 1996; COMTE, T.: "Angers a travers ses plans (1652-1813): une cité inmobile?», en PeTITfrère, C. (dir.): Images et imaginaires de la ville à l'Époque Moderne. Collection Sciences de la ville, $\mathrm{n}^{\circ}$ 15, Tours, 1998, pp. 153-173; PetiTfrère, C.: «Une ville Mise en scène: Tours d'apres l'Iconographie Générale des XVIe-XVIIe siècle», en opus cit., pp. 175-210.

110 Para el caso gallego Cf. VILLARES PAZ, Ramón: Los inventarios post mortem..., p. 75; ROZADOS FERNÁNDEZ, María Ángeles: opus cit., pp. 71 y ss.; SOBRADO CORREA, Hortensio: Las tierras de Lugo..., pp. 501 y ss.; y «L'habitation rural dans la Galice de l'Époque Moderne», Actes Colloque La maison rurale en pays d'babitat dispersé des origines aux annés soixante, (Rennes, 29-31 mai 2002), (en prensa).

111 BARDET, Jean Pierre et alii: Le Bâtiment. Enquête d'histoire Économique, XIVe-XIXe siècles. T. I: Maisons rurales et urbains dans la France traditionelle, París, 1971.

Hispania, LXIII/3, núm. 215 (2003) 825-862 
pues permiten establecer el número de estancias que conforman la vivienda, su distribución y el uso que se les daba. Los recuentos han mostrado al historiador algunas de las principales características de la vivienda campesina de Antiguo Régimen, así como su evolución en el tiempo, lo que nos da una idea de cómo se desarrollaba la vida cotidiana del momento, aunque mediante la utilización de esta documentación no resulta fácil apreciar los cambios en la organización del espacio doméstico en busca de mayor intimidad, ya que sólo en los inventarios de mayor entidad económica se diferencian varias habitaciones ${ }^{112}$.

Empero, dicha fuente ha contribuido a constatar algunas características de la vivienda rural, entre las que cabría destacar la plena cohabitación entre personas y animales, e incluso entre los propios miembros de la familia, dado el predominio de casas con una estancia única, en la que se desarrollaba toda la vida íntima de la familia, espacio de encuentros cotidianos, donde se come, se duerme, se lava, se ama, se nace o se muere. Asimismo, los inventarios mencionan múltiples útiles y enseres, aperos de labranza..., dispersos por toda la casa, confirmando que las estancias tenían un uso polivalente, y que la especialización de los espacios domésticos tardó bastante en llegar al mundo rural ${ }^{113}$.

Este tipo de fuente notarial ha permitido una aproximación a las diferencias existentes entre las viviendas campesinas de distintas zonas de Europa, comprobando las diversidades tanto interregionales, como nacionales. Así, por ejemplo, utilizando dicha documentación, mientras que John Moore observa como los campesinos ingleses vivían en casas con estancias bastante espaciosas, e incluso los jornaleros contaban con viviendas con dos estancias, sin embargo, Arlette Schweitz habla del predominio en la zona francesa de La Touraine de la estancia única, como modelo esencial de la vivienda campesina, todavía en el siglo XIX ${ }^{114}$.

De la misma forma, en el mundo urbano, los inventarios reflejan una jerarquización del espacio interior de las viviendas, que se ejerce en varios sentidos y direcciones. Puesto que la importancia de las estancias de la vivienda se reduce, por una parte, de adelante hacia atrás, y por otra, de abajo hacia arriba. Así, las salas y habitaciones que comunican con la calle ocupaban un lugar de mayor categoría que las situadas en la parte posterior, al tiempo que los pisos más bajos, a ras de suelo y en las inmediaciones de la cocina, o los más altos, reducidos y peor ventilados eran ocupados por el servicio doméstico. Y el piso principal, normalmente el de la primera planta, de techos altos, con más luz y ven-

112 RAmos PALENCIA, Fernando Carlos: «Una primera aproximación..., p. 124.

113 ROZADOS FERNÁNDEZ, María Ángeles: «Aproximación al estudio de la vivienda rural en la Galicia de los siglos XVII-XVIII", en Pedralbes, 11, (1991), pp. 109-118; SOBRADO CORREA, Hortensio: "L'habitation rural dans la Galice de l'Époque Moderne», Actes Colloque La maison rurale en pays $d$ 'babitat dispersé des origines aux annés soixante, (Rennes, 29-31 mai 2002) (en prensa).

114 MOORE, Jhon: «Rural Housing in the North Bristol Region. 1600-1750», en BAULANT, Micheline, et alii (eds.): Inventaires..., pp. 197-210; SCHWEITZ, Arlette: «De la salle commune a la chambre a coucher", en BAULANT, Micheline et alii (eds.): opus cit., pp. 319-332.

Hispania, LXIII/3, núm. 215 (2003) 825-862 
tilación, eran ocupados por los señores. Además, los recuentos de bienes han contribuido a mostrar el estilo de vida de las elites urbanas, acostumbradas a vivir en casas amplias y lujosas, con una especialización de las estancias, y un mobiliario de calidad ${ }^{115}$.

Los inventarios han ayudado a establecer tipologías básicas de la vivienda en el período moderno, atendiendo a criterios socioeconómicos; de este modo, en Barcelona, se observa la existencia de un tipo de vivienda abierta, con la cocina situada en la planta baja, con múltiples funciones de sala, comedor e incluso dormitorio, y sin una diferenciación clara entre el interior de la casa y la calle; en contraste con un modelo de vivienda noble, con la cocina en el primer piso, buscando la separación de la calle ${ }^{116}$.

Por lo que respecta al mobiliario, por su composición y su valor es un buen revelador de las estructuras y jerarquías sociales, de la coyuntura económica, así como de las mentalidades ${ }^{117}$, aunque la riqueza o pobreza no expliquen por sí mismas la totalidad de variantes que nos podemos encontrar en el mobiliario de los hogares de Antiguo Régimen, puesto que a niveles de fortuna iguales, el valor y la composición del mobiliario puede variar sensiblemente. No cabe duda de que los muebles tienen un puesto destacado en el equipamiento doméstico, tanto por su valor como por su trascendental funcionalidad, ya que los distintos elementos del mobiliario cuentan con un protagonismo activo en el cuadro de vida cotidiano de la población, al ocupar un papel de primera categoría en las funciones vitales de la alimentación, del reposo, del sueño, o del orden, entre otros aspectos.

Hasta la utilización de los inventarios, el estudio del mobiliario doméstico, y particularmente el análisis del mobiliario rural, apenas había sido objeto de investigación por parte de los historiadores, y tan sólo existían algunas aproximaciones al mobiliario tradicional hechas por historiadores del Arte y etnólogos $^{118}$. La incorporación de los recuentos en el estudio del mobiliario doméstico, junto con la de otras fuentes notariales como los contratos matrimoniales, aporta a la historiografía modernista la posibilidad de realizar estudios seriales, que permitan una aproximación tanto cuantitativa como cualitativa a las dis-

115 BARREIRO MALlón, Baudilio: «Las clases urbanas de Santiago..., pp. 449-474.

116 GARCíA Y GuÀrdiA, M.: Espai i Societet a la Barcelona pre-industrial, Barcelona, 1986; LENCINA, X:: "Activitat laboral i espai familiar en els gremis barcelonins de l' época moderna», en Pedralbes, 13, (1993), pp. 335-339.

117 PÉRET, Jacques: «Les meubles ruraux en haut Poitou au XVIIIe siècle d'après les inventaires après décès", en GoY, Joseph y WALLOT, Jean Pierre (dir.): Évolution et éclatement du monde rural..., pp. 487-498.

118 Para el caso francés Cf. VerLET, P.: Les meubles français du XVIIIe siècle, París, 1956; TARDIEU, Suzanne: Le mobilier rural traditionnel français, París, 1976. Para el caso gallego Cf. LoRENzo, Xoaquín: «Etnografía», en OTERo Pedrayo, Ramón (dir.): Historia de Galiza, Buenos Aires, 1962, vol. II, también en LoRENZo, Xoaquín: A Casa, Vigo, 1982 (concretamente apartado: A moblaxe, pp. 181-196). 
tintas tipologías de muebles existentes en las casas de las poblaciones de Antiguo Régimen ${ }^{119}$, lo que facilita el análisis de las disponibilidades mobiliarias, y que en última instancia nos puede aportar interesantes datos acerca del nivel de vida de las gentes, permitiéndonos el estudio de las mutaciones experimentadas en el transcurso de la Edad Moderna.

A juzgar por las noticias que nos proporcionan los inventarios post-mortem, en general, las viviendas de los grupos populares se caracterizaban por un mobiliario bastante escaso y austero, ante todo utilitario, reducido a lo meramente esencial, sin ninguna concesión a las comodidades, ni al lujo ${ }^{120}$; así, en el período moderno el mobiliario de cocina y del resto de dependencias de las casas campesinas era de una enorme sobriedad, reduciéndose a una mesa (cuando existía) y a unos cuantos bancos sencillos, y si acaso alguna artesa en la cocina y a una arca y un lecho o tarima para dormir en los cuartos ${ }^{121}$. En el mundo rural el mobiliario de cierta calidad únicamente estaba presente en un reducido número de viviendas, pertenecientes a campesinos acomodados, a eclesiásticos o a miembros de la nobleza; en las viviendas campesinas la tónica general es la total ausencia de elementos destinados al acomodo de sus moradores; raramente aparece una silla, un bufete, o cualquier mueble que implique cierto grado de bienestar, lo que contrasta con la mayor abundancia y calidad del mobiliario de las casas pertenecientes a los grupos privilegiados de la sociedad, que suelen contar con estancias bien decoradas, y muebles lujosos ${ }^{122}$. Algo similar se puede apreciar en el ámbito urbano, en el que los inventarios de las viviendas de la

\footnotetext{
119 Por ejemplo, a través de la utilización de los inventarios post-mortem, Jocelyne Mathieu ensaya una tipología del mobiliario doméstico existente en las casas del área canadiense de Mortagneau-Perche y la región de Quebec, centrándose en las camas. MATHIEU, Jocelyne: «Essai de typologie à partir des inventaires de biens après décès. Les lits», en Ethnologie française, t.15, $\mathrm{n}^{\circ} 3$ (JuilletSeptembre, 1985), pp. 243-250; para el caso de los contratos matrimoniales Cf. GLÜCK, Denise: «Constrution de typologies. Les armoires», en Ethnologie française..., pp. 221-234. Para el ámbito anglosajón Cf. GARRARD, R.P.: «English Probate inventoires and their use in studying the significance of the domestic interior, 1570-1700", en VAN DER WOUDE, A.D. y SCHUURMAN, Anton (eds.), Probate..., pp. 21-30; Shammas, Carole: The Pre-industrial Consumer in England and America, Oxford, 1990, pp. 159-169.

${ }_{120}$ Los objetos de lujo tenían escasa presencia en los hogares campesinos europeos y de otras áreas del mundo. Cf. DiCKINSON, J.A.: «Niveaux de vie des paysans normands et québécois au XVIIIe siècle», en GoY, J. et BOUCHARD, G., (dirs.): Famille, économie et société rurale en contexte d'urbanization (17e-20e siècle), 1990, pp. 213-224.

${ }^{121}$ Cfr. Sobrado CoRrea, Hortensio: La Tierra de Castroverde en el Antiguo Régimen: un estudio de Historia rural, Univ. de Santiago, 1992 (Memoria de Licenciatura inédita), pp. 287 y ss.; RoDRíGUEZ FERNÁNDEZ, Delfina, "Desigualdades sociales..., p. 209; Bartolomé Bartolomé, J.M.: Vino y viticultores en el Bierzo. Sociedad y estructuras económicas durante el siglo XVIII, León, 1996.

122 Para el caso gallego Cf. SAAvedra Fernández, Pegerto: «A vida cotiá da fidalguía pacega», en VI Semanas Galegas de Historia. Un percorrido pola Galicia cotiá, Santiago, 1998, (pp. 373396), p. 383; SÁNCHEZ-CANTÓN LENARD, María del Pilar: Una casa compostelana a finales del siglo XVII. Inventario de bienes, Santiago, 1997, pp. 29 y ss. Para otras zonas de España: RuBio PÉrEZ, Laureano: Arrieros maragatos. Poder, negocio, linaje y familia. Siglos XVI-XIX, León, 1995, pp. 93 y ss.
} 
nobleza, del alto clero, o de algunos miembros de la burguesía suelen hacer referencia a la existencia de mobiliario de calidad ${ }^{123}$.

Los inventarios, además de reflejar las diferencias existentes en el mobiliario y decoración de las viviendas, según la categoría socioeconómica de sus dueños, y posibilitar el establecimiento de tipologías de muebles, también permiten analizar las transformaciones experimentadas en las disponibilidades mobiliarias a lo largo del Antiguo Régimen; así, por ejemplo, a través de dicha fuente notarial se ha podido constatar como en distintas zonas de Europa, a partir de la segunda mitad del XVIII tiene lugar una mayor diversificación del mobiliario y menaje de casa. De esta forma, en varias regiones francesas los inventarios revelan como el armario, mueble de prestigio en los interiores rurales, va adquiriendo cada vez mayor difusión, generalizándose entre el mobiliario de los más acomodados, y haciendo su aparición en las viviendas campesinas, experimentando una gran expansión a finales de la centuria ${ }^{124}$, aunque no llega a sustituir al clásico cofre, que, si bien, pierde peso en las ciudades, sin embargo, se mantiene presente en casi todas las casas rurales, al igual que ocurre con las arcas en el caso español, pues en nuestro país el armario ropero tiene una difusión muy lenta a lo largo de los siglos XVIII y XIX, incluso entre sectores acomodados del mundo urbano ${ }^{125}$.

Asimismo, en las casas de varias zonas de Europa, y también de España, se puede observar una mayor presencia de artículos relacionados con el menaje de mesa y cocina, tales como cucharas, tenedores, cuchillos, platos, tazas, vasos..., así como una mayor utilización del cristal o del vidrio en tazas, copas y vasos, y una creciente difusión de la loza fina ${ }^{126}$. Igualmente, en las familias más acomodadas se observa una paulatina presencia de objetos relacionados con la calefacción e iluminación del hogar, tales como braseros, calentadores, candeleros, velones, etc., que hacen más confortables las viviendas. No obstante, los inventarios reflejan como en los hogares campesinos, prima un gran conserva-

123 BARreiro Mallón, Baudilio: «Las clases urbanas de Santiago.., pp. 456 y ss.; MARURI VILLANUEVA, Ramón: La burguesía mercantil santanderina, 1700-1850 (Cambio social y de mentalidades), Santander, 1990, pp. 140 y ss.; HERnÁNDEZ BERMEJO, M $^{\mathrm{a}}$. A.: La familia extremeña en los tiempos modernos, Badajoz, 1990, p. 238; MORENO Claverías, B.: «La Burguesía local de las letras y los negocios a través de los inventarios post-mortem. El Penedés del siglo XVIII", en TORRAS, J. y YUN, B. (Dirs.): Consumo...,op. cit., p. 84.

${ }^{124}$ PÉRET, Jacques: «Les meubles..., p. 493. Otra fuente notarial, como son los contratos matrimoniales confirma dicha tendencia, Cf. GLÜCK, Denise: opus cit., p. 221.

125 Cf. Ramos Palencia, Fernando Carlos: opus cit., p. 122; MÁuru Villanueva, Ramón: La burguesía..., p. 141; Para el caso gallego: RozAdos FernándeZ, María Ángeles: «Campo y ciudad..., p. 78; RODRíGUEZ FERNÁNDEZ, Delfina: «Desigualdades sociales..., pp. 209-210; SOBRADO CORREA, Hortensio: La Tierra de Castroverde..., p. 295.

126 ServaIS, P.: «Utensiles de cuisine et vaiselle dans les campagnes du pays de Herve aux XVIIe et XVIIIe siècles», en BAULANT, Micheline et alii (eds.): Inventaires après décès et ventes de meubles..., pp. 333-346; para el caso español Cf. entre otros: Ramos PalenCia, Fernando Carlos: .opus cit., p. 123. 
durismo en las costumbres y dado que se tienden a aprovechar las cosas hasta que ya no tienen utilidad, la posesión de objetos experimenta cambios muy lentos, con lo que la renovación y diversificación del mobiliario resulta un proceso mucho más tardío y parsimonioso que el experimentado en las ciudades. En realidad, en la España rural de la Edad Moderna los grandes beneficiados de las mejoras del nivel de vida experimentadas a partir de la segunda mitad del XVIII son las elites de la sociedad (eclesiásticos, pequeña nobleza y ricos campesinos), que muestran una preferencia por mejorar las condiciones del hábitat familiar, haciendo uso de mobiliario doméstico cada vez más completo y más variado ${ }^{127}$.

\section{LA HIGIENE Y EL VESTIDO}

Los inventarios podrían constituir una interesante fuente para aproximarnos a las prácticas higiénicas de las poblaciones de Antiguo Régimen ${ }^{128}$, sin embargo, debido a la parquedad de información que ofrecen sobre este tipo de cuestiones, su utilización se ve bastante limitada. Las referencias a instrumentos empleados para la limpieza de las viviendas o el aseo personal de sus habitantes, son muy escasas, sobre todo en los recuentos de bienes del mundo rural, en los que resulta raro encontrar descripciones de la existencia de escobas, "tinajas para lavar la ropa», orinales, o bien de alguna bacía, navaja o brocha para afeitarse, o incluso de una pieza de jabón, o de un peine. Puede que se trate de objetos que por su escaso valor no sean inventariados, pues en los inventarios de tiendas suelen tener presencia. No obstante, los recuentos permiten la aproximación a determinadas transformaciones de los hábitos cotidianos que tienen lugar en el seno de los hogares a lo largo del período moderno, y que como ocurre con la progresiva diversificación de estancias, la individualización de la cama, o el incremento de prendas de vestir por persona, y la tímida utilización de vasos individuales y cubiertos para comer, tienen una incidencia directa sobre la higiene doméstica y la salud pública. El destacado aumento experimentado a partir del siglo XVII, y principalmente a lo largo del XVIII en la posesión de camisas, pieza de gran importancia en la concepción de la época de limpieza seca, ha sido interpretado como un indicativo de mejora de la higiene particular ${ }^{129}$.

Asimismo, la progresiva presencia en las casas de utensilios para la higiene corporal (tinas, barreños, lavabos, bañeras, etc.), o la especialización de estancias para el aseo personal (letrinas, cabinas de baño, servicios...), pueden ofrecer interesantes pistas acerca de los cambios experimentados en las sociedades de

127 Pérez García, José Manuel: «Niveaux de vie et traditions culturelles..., pp. 61-92.

${ }^{128} \mathrm{La}$ posibilidad de utilizar los inventarios para el estudio de la higiene privada y el hábitat de las poblaciones de Antiguo Régimen ya había sido puesta de manifiesto por P. Gutton. Cf. GUTTON, Pierre: La societé et les pauvres. L'exemple de la généralité de Lyon (1534-1789), París, 1971, p. 61.

${ }_{129}$ Ruiz Somavilla, M. J.: El cuerpo limpio. Análisis de las prácticas bigiénicas en la España del mundo moderno, Málaga, 1993.

Hispania, LXIII/3, núm. 215 (2003) 825-862 
Antiguo Régimen en materia de higiene ${ }^{130}$. Tampoco hay que olvidar que los inventarios rurales permiten una aproximación a la higiene de la explotación, dándonos pistas sobre la cohabitación entre animales y personas, o la progresiva separación de ambos mediante la construcción de cuadras, sobre la existencia de ganado porcino, y otros animales domésticos (gallinas, patos...) sueltos en las estancias de las viviendas, o si el abono se mantiene en la casa o no, entre otros aspectos, que atañen a la higiene de las casas campesinas de Antiguo Régimen. Evidentemente los datos que ofrecen los inventarios sobre la higiene privada, resultan escasos, por lo que los investigadores que han trabajado sobre estas cuestiones han tenido que hacer uso de una diversidad de fuentes complementarias ${ }^{131}$.

Con anterioridad al uso de los inventarios, la Historia del vestido no aportaba más que la excepción y la anécdota, puesto que no iba más allá de las descripciones de la indumentaria que portaban los príncipes, sectores de la Alta Sociedad, o de ropas imaginarias ${ }^{132}$. El creciente empleo de esta rica escritura notarial posibilita la introducción de la cuantificación en el estudio del vestido de los tiempos pasados, por lo que permite la realización de estudios rigurosos que aproximan al historiador a las características del vestido, así como a la evolución en las prácticas vestimentarias de la población en el transcurso del período moderno ${ }^{133}$.

Dejando a parte fuentes como las crónicas e inventarios reales, que ofrecen información sobre el vestido de los soberanos y la nobleza, además de los inventarios post-mortem, hay otras fuentes, también de carácter notarial, susceptibles de proporcionar datos sobre la vestimenta popular tales como los testamentos, y los contratos de matrimonio. En el caso del vestido femenino, resultan de interés los contratos de' matrimonio, en los que, a veces, se especifica la ropa que se ofrece a la novia como dote ${ }^{134}$, y las descripciones pueden llegar a ser detalladas e informar de la naturaleza, el nombre, la materia, el color

130 Cf. PardailhÉ-Galabrun, Annik: opus cit., pp. 348 y ss.; Burgelin, O.: «Les outils de la toilette et le contrôle des apparences», en Panoplies di corps, Travers, $n^{\circ} 14-15$, París, (1979), pp. 25 43; ROZADOS FERNÁNDEZ, María Ángeles: «Mobiliario sanitario e higiene en la Galicia tradicional a través de los inventarios post-mortem", en Medicina Galaica, vol. 41, n 40, (1998), pp. 21-25.

${ }^{131}$ Cf. entre otros: VIGARELLO, Georges: Le propre et le sale. L'Hygienè du corps depuis le Moyen Âge, París, 1985; del mismo autor: Le sain et le malsain. Santé et mieux-être depuis le Moyen Âge, París, 1993; WRIGHT, Lawrence: Clen and decent. The fascinating history of the Batbroom and the water closet and of sundry babits, Fashions and Accesoris of the toilet principally in Great Britain, France, America, London, 1971; GuERRAND, Roger Henri: Les lieux. Histoire des commodités, París, 1985; MIKAîlofF, Nathalie: Les manières de propreté. Du Moyen Âge à nos jours, París, 1990.

132 Pellegrin, Nicole: «L'habillement rural en Poitou..., pp. 475-497.

133 B. Bennassar ya había señalado en su momento la utilidad de los inventarios para el estudio de la moda y del alcance de ésta en la sociedad. Cf. BENNASSAR, Bartolomé: "Los inventarios postmortem..., pp. 131-146.

${ }^{134}$ Cf. BarbazZA, Marie-Catherine: «Le corps vêtu: Le vêtements de la paysanne en Nouvelle Castille au tournant du XVIe siècle», en REDONDO, A. (ed.): Le corps dans la sociéte espagnole des XVle et XVVe siècles, París, 1990, pp. 73-82. 
y estado de uso de cada prenda. Los textos literarios, en ocasiones hacen referencias a la vestimenta popular, además, los reglamentos y leyes, los decretos suntuarios, permiten una aproximación a los hábitos vestimentarios de la población; asimismo, la iconografía, aunque acostumbre a presentar cierto grado de idealización, y por tanto sus limitaciones, en ocasiones logra dar una visión aproximada del vestido en tiempos pasados, y a través de la pintura, de la escultura o de grabados se puede tener una idea del tipo de vestido empleado en determinado momento de la Historia; la arqueología también sirve como recurso a emplear para conocer el vestido de la época, aunque su grado de conservación suele ser escaso y centrado principalmente en los sectores privilegiados de la sociedad ${ }^{135}$.

La escasa presencia que tiene la ropa infantil en los inventarios post-mortem, ha de compensarse con el empleo de otras fuentes como las hospitalarias y judiciales. Los registros de inscripción de niños abandonados y acogidos en Hospitales o casas cuna brindan escasas noticias sobre el vestido que llevaban los niños en el momento de ingresar en el Hospital, pero pueden ofrecer algunas pistas acerca de su apariencia ${ }^{136}$. Además, los procesos verbales elaborados por oficiales de justicia para describir las circunstancias de los abandonos de niños, pueden aportar información detallada sobre las ropas de los expósitos. Otro tipo de fuentes, aunque más raras y poco abundantes, que pueden ofrecer alguna información sobre la indumentaria infantil son algunos contratos de nodrizas, en los que se especifique la ropa que deben llevar los niños; también son susceptibles de utilización cuentas de tutela de niños, en las que se enumere el guardarropa infantil.

Los recuentos de bienes han permitido la aproximación del historiador a determinados aspectos del vestido de las sociedades de Antiguo Régimen, tales como el número de prendas por persona, la tipología del vestido, o los tejidos y colores predominantes, comprobando las diferencias existentes en el vestir entre los habitantes del mundo rural y de las ciudades ${ }^{137}$, así como los cambios experimentados a lo largo del período moderno. No cabe duda, además, de que el vestido constituye un interesante revelador social ${ }^{138}$, una imagen de la persona que lo porta, signo de reconocimiento y de discriminación ${ }^{139}$, por lo que su

135 RocHE, Daniel, La culture des apparences. Une bistoire du vêtement (XVIIe-XVIIIe siècle), París, 1989 , pp. 19 y ss.

136 PeLLEGRIN, Nicole: «Habiller les enfants en Poitou au XVIIIe siècle», en 111e congrès National des societés Savantes, Poitiers, 1986, pp. 59-75.

${ }_{137}$ Sobre las diferencias en el vestido entre campo y ciudad vid. para finales del período medieval. PIPONNIER, François: «Matieres premiers du costume et groupes sociaux Bourgogne XIVe-XVe siecles», pp. 271-290. Para el caso gallego Cf. RoZADOS FERNÁNDEZ, María Ángeles: opus cit., p. 112.

138 GARNOT, Benoît: La culture matérielle..., p. 97.

139 Deslandres, Yvonne: Le costume image de l'bomme, París, 1976, pp. 170 y ss.; DelaPORTE, Yves: «Le signe vestimentaire», en $L$ 'bomme, Juil-Sept., (1980), XX (3), pp. 109-142. 
análisis también puede aproximarnos al status político, social, económico o profesional de los distintos miembros de las poblaciones de Antiguo Régimen.

Los inventarios han contribuido a corroborar de forma documentada la gran austeridad de las ropas del campesinado europeo del período moderno, así como una serie de rasgos más o menos comunes de su indumentaria, tales como las formas estabilizadas del vestido campesino, tanto femenino como masculino, la naturaleza local de las producciones textiles y domésticas, así como el predominio de tonalidades oscuras, y del mal estado de las ropas populares ${ }^{140}$. Los recuentos han permitido constatar como la abundancia de prendas no solía caracterizar a las casas campesinas, y la mayoría de la gente del campo no poseía más que un ejemplar de cada pieza de ropa, careciendo de vestidos de repuesto, e incluso algunos viéndose obligados a vestir ropas ajenas ${ }^{141}$, lo que tenía graves consecuencias sobre el estado de la ropa, así como en la higiene personal de los campesinos. Debido a esa escasa disponibilidad de prendas de vestir, la mayor parte de la ropa presentaba un deplorable estado de conservación. Los recuentos reflejan como en muchos casos las ropas inventariadas son conceptuadas como viejas, raídas y sucias ${ }^{142}$. A causa de la precariedad de medios las ropas eran guardadas durante muchos años, aprovechándolas a pesar de su mal estado, mediante la reparación de las prendas por parte de traperos y costureros de viejo, o reutilizándolas para elaborar ropas para niños ${ }^{143}$.

Los inventarios también han permitido rastrear los cambios experimentados en el vestido de la población, tanto urbana como rural, del período moderno, facilitando la observación de transformaciones en la tipología y número de prendas, en el tipo de tejidos o en los colores. Entre otros muchos aspectos, dicha fuente ha hecho posible a los historiadores constatar ciertas transformaciones en el vestido popular en el curso del siglo XVIII, tales como un incremento en el número de prendas por persona, así como una serie de cambios en el tipo de tejidos y una mayor diversificación de prendas y colores ${ }^{144}$, algo que también confirman otras fuentes como los contratos matrimoniales ${ }^{145}$. En el

\footnotetext{
140 GARNOT, Benoît: opus cit., p. 97 y ss.

$141 \mathrm{Ej} .:$ «y en cassa de Gregorio de Ardariz, de Milleirós, una saia de palmilla usada que avia llevado prestada...» AHUS, F.P. 3215, fol. 110v. Cfr. VILlares PAZ, Ramón: Los inventarios..., p. 76.

${ }_{142}$ Ej.: (27-IV-1760) Invent. de Domingo Fernández, $v^{\circ}$ de Villameixide, concejo de Navia (Lugo): «un vestido viejo de cada día...» AHPL, Protocolos, Leg. 1476/3.

143 Pellegrin, Nicole: "Chemises et chiffons. Le vieux et le neuf en Poitou et Limousin XVIIIe-XIXe siècle», en Ethnologie française, t. 16, n 3, Juillet-Sept., (1986), pp. 283-294.

${ }_{144}$ Para el caso español Cf. TORRA FernándeZ, Lídia: «Pautas de consumo textil..., p. 98; RAMOS PALENCIA, Fernando Carlos: «Una primera aproximación al consumo..., p. 125; LENCINA PÉREZ, Xavier: «Los inventarios post-mortem..., p. 57.

${ }^{145}$ Cf. TORRAS, Jaume; DURAN, Monserrat y TORRA, Lídia: «El ajuar de la novia. El consumo de tejidos en los contratos matrimoniales de una localidad catalana, 1600-1800», en TORRAS, Jaume y Yun CASAlilla, Bartolomé (dirs.): Consumo..., pp. 61-69; GarCía Fernández, Máximo: «Los bienes dotales en la ciudad de Valladolid, 1700-1850. El ajuar doméstico y la evolución del consumo y la demanda», en Ibídem, pp. 133-158.
} 
mundo urbano, en la ropa femenina, la lana deja paso al algodón y a la seda, y las prendas se hacen cada vez más ligeras, flexibles y elegantes, multiplicándose los accesorios y surgiendo una idea de consumo, de refinamiento y de las apariencias, que señala cada vez con mayor claridad la condición social de sus portadores $^{146}$; aunque, en el mundo rural la miseria de los campos no permite apenas variaciones, y la ropa continua siendo hecha con los materiales locales, por lo que la lana y el lino siguen teniendo gran importancia en la confección de las ropas del campesinado ${ }^{147}$. También se constata cierta diversificación de los colores, y pronto el blanco, junto con otros tonos como el azul, amarillo y verde, triunfan en la ciudad ${ }^{148}$; si bien, en el campo, las tonalidades oscuras, evocadoras de los colores de la tierra (marrones, ocres, grises, negro), sigan siendo las más empleadas en la elaboración de las ropas de los campesinos, pues la rudeza de los trabajos impone la utilización de ropas sólidas y sufridas, lo que da escaso pie a la fantasía ${ }^{149}$.

Por lo tanto, si bien en el XVIII para algunos autores, en países como Francia se asista a una verdadera revolución del vestido, en la que se incrementa y diversifica el guardarropa popular, lo cierto es que la cultura vestimentaria y textil del campesinado es un verdadero bricolage, que aunque recibe influencias de lo que ocurre en las ciudades, adapta siempre los cambios a las necesidades puntuales del medio rural, por lo que la inicial imitación en las forma de vestir de las elites que tiene lugar en la ciudad, es seguida con cierto retraso en el campo por medio del circuito de las ferias y mercados; sin embargo en el mundo rural el vestido, al igual que ocurre con otros aspectos de la cultura material arrastre grandes continuidades a lo largo del período moderno y aún del contemporáneo, motivadas, más por la imposibilidad económica de acceder a los nuevos artículos que, a resistencias culturales ${ }^{150}$.

Por lo que respecta a la vestimenta infantil, como ya se ha comentado páginas atrás, los inventarios apenas ofrecen datos, pues la ropa de niños es una gran ausente de los recuentos. No obstante, en ocasiones aparecen pruebas de que las ropas de los adultos difuntos son reaprovechadas para hacer ropa para los niños; son varios los ejemplos de la reutilización de camisas y otras prendas de vestir de adultos para que empleen sus hijos. En general, los historiadores que han estudiado el vestido infantil en el pasado, hablan de que de la Edad Media hasta finales del XVII, los niños eran vestidos igual que los mayores, con ropa de

146 RocHE, Daniel: «L'invention du linge au XVIIIe siècle», en Ethnologie française, t. 16, no 3 , Juillet-Sept., (1986), pp. 227-238.

147 Para el caso gallego Cf. CARmona BADía, X.: «L'industria rurale domestica in Galizia (secoli XVIII e XIX)", en Quaderni Storici, 52, 1983, pp. 11-24; SAAVEDRA, Pegerto: La vida cotidiana ..., op. cit.; SOBRADO CORREA, Hortensio: Las tierras de Lugo..., pp. 305 y ss.; para el caso francés Cf. GARNOT, Benoît: Le peuple au Siècle des Lumières. Échec d'un dressage culturel, París, 1990, pp. 154 y ss.

${ }_{148}$ Cf. Garnot, Benoît: Un déclin: Chartres au XVIIIe Siècle, París, 1991, pp. 216 y ss.

149 ROCHE, Daniel: Histoire des choses banales..., p. 218.

150 SAAVEDRA FernándeZ, Pegerto: La vida cotidiana..., p. 148.

Hispania, LXIII/3, núm. 215 (2003) 825-862 
adultos en miniatura ${ }^{151}$. El empleo de la iconografía y de otras fuentes de carácter escrito muestra esta tendencia; y autores como el propio Philippe Ariès han hecho una demostración a partir de las pinturas del período moderno ${ }^{152}$.

En definitiva, a modo de recapitulación, se puede decir que lo esencial del estudio de las transformaciones experimentadas en las prácticas de la vida cotidiana en el transcurso del período moderno reposa, pues, sobre los inventarios. Historiadores como D. Roche, J. Sentou, R. Lick o R. Mousnier, entre otros, han utilizado los inventarios para analizar las modificaciones experimentadas en el consumo de poblaciones como las de París, Toulouse o Coutan$\operatorname{ces}^{153}$, y muchos otros trabajos posteriores inscritos tanto en la historiografía francesa, como en la de otros países europeos han hecho uso de estas ricas fuentes notariales para aproximarse a la cultura material de las poblaciones urbanas y rurales del Antiguo Régimen.

A través de estas páginas se ha comprobado como el inventario post-mortem es una fuente ampliamente elogiada por la riqueza de sus datos, pero asimismo muy criticada por sus deficiencias y omisiones. Son muchos los reproches que los historiadores han hecho en contra de los problemas que plantea el uso de este tipo de fuente notarial, tales como sus grados de representatividad y fiabilidad, falta de homogeneidad, así como a las omisiones más o menos sistemáticas de información que presentan, o a la serie de lagunas que dificultan su empleo para el estudio de distintos aspectos materiales del cuadro de vida; problemas que es necesario tener presentes, pero que en parte son superables, si el historiador sabe hacer un uso adecuado y racional de la fuente, y es plenamente consciente de sus limitaciones.

En España el estudio de la cultura material y el consumo de las poblaciones de Antiguo Régimen, constituye un tema escasamente atendido por la historiografía modernista, con relación a otros ámbitos de investigación europeos, - sobre todo en lo referente al mundo rural-, no obstante los inventarios han permitido que hoy en día tengamos un conocimiento un poco más amplio acerca de cómo era la alimentación, la vivienda y el mobiliario doméstico, o la higiene y el vestido de aquellas personas que vivieron en España entre los siglos XVI y XVIII.

La escasez de fuentes y la parquedad de las informaciones que éstas proporcionan, ha hecho que tradicionalmente, la historiografía modernista haya prestado una menor atención a la alimentación de los grupos populares, y particularmente a los del mundo rural. A pesar de que la información contenida en los

151 BOUCHER, François: Histoire du costume en occident, de l'Antiquité à nos jours, París, 1965; Guidon, A.: L' Habillé et le nu. Pour une éthique du vêtir et du dénuder. Ottawa, 1997, pp. 49 y ss.

${ }_{152}$ ARIÈs, Philippe: $L$ 'enfant et la vie familiale sous l'Ancien Régime, París, 1975.

153 Cf. Roche, Daniel: Le peuple..., p. 60; SENTOU, Jean: Fortunes et groupes sociaux á Toulouse sous la Révolution, Toulouse, 1969; LICK, R.: «Les interieurs domestiques dans la seconde moitié du XVIIIe siècle», en Annales de Normandie, 1970, pp. 293-302; MOUSNIER, Roland: La stratification sociale á París au XVIIIe Siècle, París, 1976. 
inventarios rurales presenta grandes limitaciones para el estudio de este tema, sin embargo su empleo cruzado con otras fuentes ha contribuido a corroborar como la alimentación popular de Antiguo Régimen presentaba unas acusadas diferencias regionales y comarcales, caracterizándose desde una óptica actual por su gran irregularidad a lo largo del año, así como por una dieta monótona, poco equilibrada y escasamente diversificada, con un gran peso de los cereales como alimentos de base, y exiguo consumo de carne y pescado; dieta que contrastaba con la de otros sectores de la sociedad, que como los eclesiásticos, o la pequeña nobleza e hidalguía, acostumbraban a consumir una mayor variedad y calidad de alimentos. Asimismo, los inventarios también nos han ofrecido a los historiadores algunas pistas sobre el consumo de nuevos productos y su difusión entre la sociedad de la época, lo que ha permitido el seguimiento de la introducción y evolución de nuevas plantas como el maíz y la patata, o de productos coloniales como el café o el chocolate.

De igual modo, pese a las limitaciones de información que presenta esta fuente notarial, el empleo de los inventarios ha posibilitado al historiador una aproximación a las características de la vivienda y del mobiliario doméstico, así como a sus transformaciones a lo largo del período moderno. Dicha fuente ha contribuido a constatar las diferencias entre la vivienda rural y urbana de la época, perfilando algunos de sus caracteres básicos, en cuanto a tipología, materiales de construcción o distribución del espacio, entre otros. Los inventarios también confirman que durante el período moderno en muchas casas las estancias tenían un uso polivalente, y que la especialización de los espacios domésticos tardó bastante más en llegar al mundo rural que al urbano. Asimismo, la incorporación de los inventarios en el estudio del mobiliario doméstico, ha mostrado como las viviendas de los grupos populares se caracterizaban por un mobiliario bastante escaso y austero, ante todo utilitario, reducido a lo meramente esencial, sin ninguna concesión a las comodidades, ni al lujo, lo que contrasta con la mayor abundancia y calidad del mobiliario de las casas pertenecientes a los grupos privilegiados de la sociedad, que suelen contar con estancias bien decoradas, y muebles lujosos.

Con anterioridad al uso de los inventarios, la Historia del vestido apenas iba más allá de la anécdota. El creciente empleo de esta rica escritura notarial ha hecho posible la introducción de la cuantificación en el estudio del vestido, por lo que, pese a las grandes limitaciones de información que presenta dicha fuente para el estudio de estos aspectos, su utilización permite la realización de estudios rigurosos que aproximan al historiador a las características del vestido, así como a la evolución en las prácticas vestimentarias de la población en el transcurso del período moderno:

Pero además de constatar algunas de las características de la alimentación, de la vivienda o del vestido, los inventarios han permitido el análisis en la larga duración de este tipo de indicadores del nivel de vida de las poblaciones, contribuyendo a corroborar como en el siglo XVIII tiene lugar una revolución de 
los objetos, pero también cierta revolución de las mentalidades, que va tomando cuerpo de forma mucho más temprana en el mundo urbano que en el rural; en el campo los cambios son más lentos que en la ciudad, pues en la mentalidad campesina está aprovechar lo que tiene hasta que sea prácticamente inservible, por lo que la vajilla, los muebles, la ropa y otros objetos de uso cotidiano se conservan durante períodos muy largos de tiempo, y las novedades se introducen muy lentamente ${ }^{154}$. La mejora del nivel de vida experimentado en muchas áreas de Europa en la segunda mitad del XVIII permite a determinados sectores de la sociedad algunos arreglos en las viviendas, y la compra de varios muebles, con lo que el mobiliario doméstico tiende hacia una mayor racionalidad y confort; también se asiste a un aumento en la adquisición de utensilios de cocina y vajilla, y a una mayor abundancia y diversificación de ropa ${ }^{155}$, tanto de casa como de vestir, por lo que los objetos se multiplican, y se camina hacia una sociedad del consumo y de la imitación, hacia una revolución de las apariencias ${ }^{156}$.

Por lo tanto, es evidente que las condiciones de vida materiales de las sociedades de Antiguo Régimen varían según los lugares y según los medios, y ya se trate de las características del alojamiento, de la alimentación, o del vestido, los inventarios post-mortem constituyen una fuente privilegiada para aproximar al historiador a la realidad cotidiana. No cabe duda, pues, de que los inventarios suponen una fuente indirecta con grandes limitaciones, pero que, sin embargo, adecuadamente utilizados, y cruzando los datos que aportan con algún otro tipo de fuente, han contribuido a resolver problemas de información antes insolubles en los campos de la Historia rural, de la Historia urbana y de la Historia de las mentalidades ${ }^{157}$, y todavía pueden seguir aportando a los modernistas valiosos datos acerca de la vida cotidiana de las sociedades de Antiguo Régimen.

154 WARO-DeSJARDINS, Françoise: «Permanences et mutations de la vie domestique au XVIIIe siècle: Un village de Vexin français», en Revue d'Histoire moderne et contemporaine, t. 40, (J.-M. 1993), pp. 3-29.

155 Servais, P.: «Utensiles de cuisine et vaiselle dans les campagnes du pays de Herve aux XVIIe et XVIIIe siècles», en BAULANT, Micheline et alii (eds.): Inventaires après décès et ventes de meubles..., pp. 333-346.; Pellegrin, Nicole: «Chemises et chiffons..., pp. 283-294; Roche, Daniel: «L'invention du linge..., pp. 227-238; RAMOS PALENCIA, Fernando Carlos: opus cit., pp. 123-125; TORRA FernándeZ, Lídia: «Pautas de consumo textil..., p. 98; LenCiNA PÉrEZ, Xavier: «Los inventarios post-mortem..., p. 57.

156 Vid. nota 20.

157 EIRAS ROEL, Antonio: «La documentación de protocolos notariales en la reciente Historiografía Modernista», en Estudis Històrics $i$ Documents dels arxius de protocols, VIII, Barcelona, 1980, (pp. 7-27), p. 14.

Hispania, LXIII/3, núm. 215 (2003) 825-862 